\title{
Theoretical Interpretation of Polarized Light-Induced Supramolecular Orientation on the Basis of Normal Mode Analysis of Azobenzene as Hybrid Materials in PMMA with Chiral Schiff Base $\mathrm{Ni}(\mathrm{II}), \mathrm{Cu}(\mathrm{II})$, and $\mathrm{Zn}(\mathrm{II})$ Complexes
}

\author{
Maiko Ito ${ }^{1}$, Takashiro Akitsu"," and Mauricio A. Palafox ${ }^{2,3}$ \\ ${ }^{1}$ Department of Chemistry, Faculty of Science, Tokyo University of Science, 1-3 Kagurazaka, Shinjuku-ku, \\ Tokyo 162-8601, Japan \\ ${ }^{2}$ Departamento de Química-Física I, Facultad de Ciencias Químicas, Universidad Complutense de Madrid, \\ Madrid-28040, Spain \\ ${ }^{3}$ Nofima AS, Norwegian Institute of Food, Fisheries and Aquaculture Research, Osloveien 1, 1430 Ås, \\ Norway
}

\begin{abstract}
We have prepared hybrid materials of azobenzene and chiral Schiff base Ni(II), Cu(II), and Zn(II) complexes and investigated their linearly or circularly polarized UV (ultraviolet) light-induced supramolecular orientation with polarized electronic and IR spectra or CD (circular dichroism) spectra. The experimental FT-IR (Fourier transfer-infrared) spectra of azobenzene molecules were recorded at room temperature, and the results were compared with quantum chemical theoretical values using B3LYP, M052X, and M062X DFT (density functional theory) methods. The interaction of azobenzene with PMMA was simulated. Molecular geometry, vibrational wavenumbers, and thermodynamic parameters were calculated in all these systems. With the help of specific scaling procedures for the computed wavenumbers, the experimentally observed FT-IR bands were analyzed and assigned to different normal modes of the molecule. Most modes had wavenumbers in the expected range, and the error obtained was in general very low. Several general conclusions were deduced.
\end{abstract}

Keywords: Chirality, azobenzene, polarized light, IR spectra, DFT.

\section{INTRODUCTION}

As a component of photofunctional organic/ inorganic hybrid materials, azobenzene (AZ), a typical photochromic dye, is a molecule of great interest at present. Therefore, many theoretical studies using $a b$ inito, DFT, and molecular dynamic methods have been reported, together with spectroscopic studies of the ground and excited states [1-18]. One of the advantages of these hybrid materials may be that it is possible to introduce the optical function of photofunctional organic compounds to non-photoactive inorganic metal complexes showing attractive electronic properties or functions [19-22].

In this context, we have developed light-induced molecular orientation and supramolecular chiral ordering by irradiating polarized UV light to photofunctional hybrid materials containing the photoresponsive molecules and metal complexes in polymer film [23-32]. We have tested various conditions of complexes, azo-dyes, and light irradiation. For example, we synthesized organic/inorganic hybrid materials composed of chiral Schiff base $\mathrm{Co}(\mathrm{II}), \mathrm{Ni}(\mathrm{II})$,

*Address correspondence to this author at the Department of Chemistry, Faculty of Science, Tokyo University of Science, 1-3 Kagurazaka, Shinjuku-ku, Tokyo 162-8601, Japan; Tel: +81-3-5228-8271;

E-mail: akitsu@rs.kagu.tus.ac.jp
$\mathrm{Cu}(\mathrm{II})$, or $\mathbf{Z n}(\mathrm{II})$ complexes and $\mathbf{A Z}$ in polymethyl methacrylate (PMMA) cast films and observed linearly or circularly polarized light-induced molecular orientation [33] by means of polarized electronic (UVvis) or IR spectroscopy [34]. By carefully neglecting solid-state artifacts, CD spectroscopy may be effective in observing chiral components separately [35-37]. Thus, if it is possible to create functional materials that can control the various functions of inorganic metal complexes via light or their physical (spatial) information, such materials will be desirable for the production of new devices.

However, polarized UV-vis spectra are not able to individually observe each component for the following reasons: (1) there is overlap of the $\pi-\pi^{*}$ and $n-\pi^{*}$ bands of the $\mathbf{A Z}$ and complexes and (2) the $\mathrm{Zn}(\mathrm{II})$ complex has no $\mathrm{d}$-d- band. Therefore, IR spectroscopy was employed for the selective observation of $\mathrm{C}=\mathrm{N}$ bands of complexes and $\mathrm{N}=\mathrm{N}$ bands of $\mathbf{A Z}$ as composites in PMMA films. Using TD-DFT calculations, theoretical interpretation of IR spectra on the basis of normal vibration is required for reliable assignment of the IR spectra.

Here we have synthesized new chiral Schiff base $\mathrm{Ni}(\mathrm{II}), \mathrm{Cu}(\mathrm{II})$, and $\mathrm{Zn}(\mathrm{II})$ complexes. Incorporating $-\mathrm{OH}$ 
groups results in enhanced intermolecular interaction with the PMMA matrix [38, 39]. The molecular design aims to induce supramolecular orientation by linearly or circularly polarized UV light irradiation. In addition, using normal mode AZ analysis in PMMA film (not in the gas phase) and simulated IR spectra of the complexes by TD-DFT calculation, we could individually observe components in the hybrid material. To the best of our knowledge, this is the first attempt at selective interpretation of induced molecular orientation after polarized UV light irradiation.
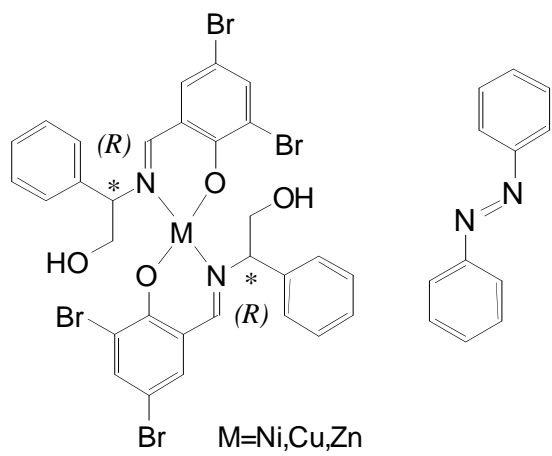

Scheme 1: Structures of chiral Schiff base complexes (abbreviated as $\mathbf{N i}, \mathbf{C u}$, and $\mathbf{Z n}$ ) [left] and $\mathbf{A Z}$ (trans-form) [right].

\section{METHODS}

\section{General Procedures}

Chemicals of the highest commercial grade available (solvents from Kanto Chemical, organic compounds from Tokyo Chemical Industry, and metal sources from Wako) were used as received.

\section{Preparation of bis(N-2-hydroxy-1-phenyl-3,5- dibromosalicydenaminato)nickel(II) (Ni)}

To a solution of 3,5-dibromosalicylaldehyde $(0.2799$ $\mathrm{g}, 1.000 \mathrm{mmol})$ dissolved in methanol $(50 \mathrm{~mL}),(R)-(-)-$ 2-phenylglycinol $(0.1372 \mathrm{~g}, 1.000 \mathrm{mmol})$ was added and stirred at $313 \mathrm{~K}$ for $2 \mathrm{~h}$ to give a yellow solution of the ligand. Nickel(II) acetate tetrahydrate $(0.1246 \mathrm{~g}$, $0.5000 \mathrm{mmol}$ ) was added to the resulting solution to give a green solution of the complex. After stirring for 4 $\mathrm{h}$, this crude green compound was filtered and recrystallized from methanol. Yield: $0.2689 \mathrm{~g}(62.9 \%)$. Anal. Found: C, 42.22; H, 2.46; N, 3.08\%. Calcd. for $\mathrm{C}_{30} \mathrm{H}_{24} \mathrm{NiBr}_{4} \mathrm{~N}_{2} \mathrm{O}_{4} \mathrm{C}, 42.15 ; \mathrm{H}, 2.83 ; \mathrm{N}, 3.28 \%$. IR [Nujol mull $\left(\mathrm{cm}^{-1}\right)$ ]: $721(\mathrm{w}), 1144(\mathrm{w}), 1211(\mathrm{w}), 1304(\mathrm{w})$, $1377(\mathrm{~m}), 1462$ (s), 1629 (w) (C=N), 2853 (s), 2925 (s). Electronic spectra (nm): 394, 595 (acetone); 238, 249, 392, 596 (methanol); 250, 393, 608 (chloroform).

\section{Preparation of bis(N-2-hydroxy-1-phenyl-3,5- dibromosalicydenaminato) copper(II) (CU)}

To a solution of 3,5-dibromosalicylaldehyde $(0.2799$ $\mathrm{g}, 1.000 \mathrm{mmol})$ dissolved in methanol $(50 \mathrm{~mL}),(R)-(-)-$ 2-phenylglycinol $(0.1372 \mathrm{~g}, 1.000 \mathrm{mmol})$ was added and stirred at $313 \mathrm{~K}$ for $2 \mathrm{~h}$ to give a yellow solution of the ligand. Copper(II) acetate monohydrate $(0.0998 \mathrm{~g}$, $0.500 \mathrm{mmol}$ ) was added to the resulting solution to give a green solution of the complex. After stirring for $4 \mathrm{~h}$, this crude green compound was filtered and recrystallized from methanol. Yield: $0.2123 \mathrm{~g}$ (49.4\%). Anal. Found: $\mathrm{C}, 39.22 ; \mathrm{H}, 2.31 ; \mathrm{N}, 2.70 \%$. Calcd. for $\mathrm{C}_{30} \mathrm{H}_{24} \mathrm{CuBr}_{4} \mathrm{~N}_{2} \mathrm{O}_{4} ; \mathrm{C}, 39.00 ; \mathrm{H}, 2.48 ; \mathrm{N}, 2.46 \%$. IR [Nujol mull $\left(\mathrm{cm}^{-1}\right)$ ]: $721(\mathrm{w}), 1151(\mathrm{w}), 1376(\mathrm{~m}), 1462$ (s), $1628(\mathrm{w})(\mathrm{C}=\mathrm{N}), 2854$ (s), 2925 (s). Electronic spectra $(\mathrm{nm})$ : 386, 625 (acetone); 249, 384, 613 (methanol); 249, 389, 607 (chloroform).

\section{Preparation of bis(N-2-hydroxy-1-phenyl-3,5- dibromosalicydenaminato)zinc(II) (Zn)}

To a solution of 3,5-dibromosalicylaldehyde $(0.2799$ $\mathrm{g}, 1.000 \mathrm{mmol})$ dissolved in methanol $(50 \mathrm{~mL}),(R)-(-)$ 2-phenylglycinol $(0.1372 \mathrm{~g}, 1.000 \mathrm{mmol})$ was added and stirred at $313 \mathrm{~K}$ for $2 \mathrm{~h}$ to give a yellow solution of the ligand. Zinc(II) acetate dihydrate $(0.1097 \mathrm{~g}, 0.5000$ $\mathrm{mmol}$ ) was added to the resulting solution to give a yellow solution of the complex. After stirring for $4 \mathrm{~h}$, this crude yellow compound was filtered and recrystallized from methanol. Yield: $0.3284 \mathrm{~g}(77.1 \%)$. Anal. Found: C, 41.58; $\mathrm{H}, 2.46 ; \mathrm{N}, 3.06 \%$. Calcd. for $\mathrm{C}_{30} \mathrm{H}_{24} \mathrm{ZnBr}_{4} \mathrm{~N}_{2} \mathrm{O}_{4} \mathrm{C}, 41.82 ; \mathrm{H}, 2.81 ; \mathrm{N}, 3.25 \%$. IR [Nujol mull $\left(\mathrm{cm}^{-1}\right)$ ]: $702(w), 1028(w), 1052(w), 1146(w)$, 1212 (w), 1301 (w), $1377(\mathrm{~m}), 1461$ (m), $1610(\mathrm{w})$ $(\mathrm{C}=\mathrm{N}), 2854(\mathrm{~s}), 2923(\mathrm{~s})$. Electronic spectra $(\mathrm{nm}): 387$ (acetone); 240, 385 (methanol); 248, 388 (chloroform).

\section{Preparation of Hybrid Materials, $\mathrm{Ni}+\mathrm{AZ}+\mathrm{PMMA}$, $\mathrm{Cu}+\mathrm{PMMA}$, and $\mathrm{Zn}+\mathrm{AZ}+\mathrm{PMMA}$}

For measurements of UV-vis spectra, acetone solutions of $\mathbf{A Z}\left(1.83 \times 10^{-3} \mathrm{~g}, 1.00 \times 10^{-5} \mathrm{~mol}\right)$ with PMMA and acetone solutions of $\mathrm{Ni}\left(4.27 \times 10^{-3} \mathrm{~g}, 5.0 \times\right.$ $\left.10^{-6} \mathrm{~mol}\right), \mathbf{C u}\left(4.29 \times 10^{-3} \mathrm{~g}, 5.0 \times 10^{-6} \mathrm{~mol}\right)$, or $\mathbf{Z n}$ $\left(4.26 \times 10^{-3} \mathrm{~g}, 5.0 \times 10^{-6} \mathrm{~mol}\right)$ with PMMA were mixed and cast onto a glass slide at room temperature.

\section{Physical Measurements}

Elemental analyses for $\mathrm{C}, \mathrm{H}$, and $\mathrm{N}$ were conducted using a Perkin-Elmer 2400Il CHNS/O analyzer at Tokyo University of Science. Infrared (IR) spectra were recorded as $\mathrm{KBr}$ on a JASCO FT-IR 4200 and spectrophotometer equipped with a polarizer with a range of $4000-400 \mathrm{~cm}^{-1}$ at $298 \mathrm{~K}$. Absorption 
electronic (UV-vis) spectra were measured on a JASCO V-570 UV/VIS/NIR spectrophotometer or a JASCO V-650 UV/VIS spectrophotometer equipped with a polarizer with a range of $800-220 \mathrm{~nm}$ at $298 \mathrm{~K}$. Photo-illumination was performed using a lamp (1.0 $\mathrm{mW} / \mathrm{cm}^{2}$ ) with optical filters (UV $\lambda=200-400 \mathrm{~nm}$ ). Thus, a sample was produced using optical fibers and a polarizer through optical filters. Angles of polarizer denote the direction of electric vector of linearly polarized light from vertical line.

\section{Computational Details}

Calculations were performed using the B3LYP, M052X, and M062X density functional (DFT) methods implemented in the GAUSSIAN 09 [40] program package using the Quipu computer of the Computational Center at the Complutense University of Madrid. The standard parameters of the UNIX version of this package were used. The DFT methods are the most adequate because they provide a compromise between the desired chemical accuracy and the heavy demands placed on the computer time and power. In addition, DFT methods have been used satisfactorily in many studies [41-45]. The B3LYP DFT method was chosen because several studies have shown that the data obtained using this method are in good agreement with those obtained using other costly computational methods (such as MP2), and it predicts vibrational wavenumbers better than HF and MP2 methods [4650]. The M052X and M062X methods are members of the M05 and M06 family of DFT methods recently developed by Zhao, Truhlar, and Schultz, which were designed to yield broad applicability in the field of chemistry [51].

Several basis sets were used, starting from 6$31 G(d, p)$ to $6-311++G(3 d f, p d)$. The $6-31 G(d, p)$ set represents a compromise between the accuracy and computational cost; thus, it was the base set selected as the reference for all of the calculations. The Berny optimization algorithm was used under the TIGHT convergence criterion. Conformational equilibrium at 298.15 K was evaluated by means of the Boltzmann distribution. The natural NBO procedure was employed for the determination of the atomic charges $[52,53]$.

Wavenumber calculations were performed on all optimized conformers to confirm the stationary points as local minima on the potential energy landscape and to calculate Gibbs energies $\Delta G$ as the sum of the electronic and thermal free energies. These were performed at the same level as the respective optimization process and by analytical evaluation of the second derivative of the energy with respect to nuclear displacement. The absence of imaginary wavenumbers confirmed the optimized conformations to be local minima. Relative energies were obtained by adding zero-point vibrational energies (ZPEs) to the total energy. For the calculation of ZPEs, the wavenumbers were retained unscaled.

\section{RESULTS AND DISCUSSION}

\section{Geometry Optimization of AZ Molecule. Isolated State}

The optimized bond lengths, bond angles, and torsional angles calculated in the cis and trans orientation of $\mathbf{A Z}$ at the $\mathrm{B} 3 \mathrm{LYP} / 6-31 \mathrm{G}(\mathrm{d}, \mathrm{p})$ and $B 3 / Y P / 6-311+G(2 d, p)$ levels are listed in Table 1 , while the labeling of the atoms is plotted in Figure $\mathbf{1}$. Because of the symmetry of the molecule, only the values for one side of the structure are provided in Table 1. The computed values with the two basis sets were, in general, very close and were in accordance with the data reported for related molecules. The differences were in accordance with the average error of this method. These values for the isolated state are in agreement with previous theoretical [54] and experimental results obtained by electron diffraction [55].

In the trans orientation, the structure is fully planar, and all the torsional angles are $0^{\circ}$ or $180^{\circ}$. Both benzene rings are independent, and one ring has no influence on the other in the planarity of the structure. However, the nitrogen atom attached to $\mathrm{C} 6$ has a noticeable influence on the aromaticity of the ring. The nitrogen atom withdraws negative charge on the C6 atom and thus changes it to a positive value, $0.093 \mathrm{e}^{-}$ (where $\mathrm{e}^{-}$is the charge of an electron) with the 6$311+\mathrm{G}\left(2 \mathrm{~d}, \mathrm{p}\right.$ ) basis set (on C3, it is $-0.185 \mathrm{e}^{-}$) (Table 2). This leads to a shortening of $\mathrm{C} 1-\mathrm{C} 2$ and $\mathrm{C} 4-\mathrm{C} 5$ e.g. a slight quinonoided characteristic on the benzene ring. This effect has also been observed in the aniline molecule [56]. The nitrogen atom also affects the C1C6 length, which is slightly longer $(0.005 \AA)$ than the C5-C6 length. Because of the short $\mathrm{N}=\mathrm{N}$ bond, the $\mathrm{C}-\mathrm{N}$ bond length is slightly longer than that found in the aniline molecule: at the B3LYP/6-31G(d,p) level, 1.419 $\AA$ vs. $1.398 \AA$ in aniline [56]. With a longer C-N bond, the effect of the nitrogen atom on the ipso angle C-C2$C$ is smaller than that in the aniline molecule: $120.4^{\circ}$ vs. $118.6^{\circ}$ in aniline. Because of the symmetry of the structure, the dipole moment is 0.0 (Table 3 ). 
Table 1: Optimized Geometrical Parameters $\left(\AA{ }^{\circ}{ }^{\circ}\right)$ at B3LYP Level of AZ

\begin{tabular}{|c|c|c|c|c|c|}
\hline \multirow[b]{2}{*}{ Parameters } & \multicolumn{2}{|c|}{ cis } & \multicolumn{2}{|c|}{ Trans } & \multirow{2}{*}{$\begin{array}{c}\text { Trans in PMMA } \\
6-31 \mathrm{G} \\
(\mathrm{d}, \mathrm{p})\end{array}$} \\
\hline & $\begin{array}{c}6-31 G \\
(d, p)\end{array}$ & $\begin{array}{c}6-311+G \\
(2 d, p)\end{array}$ & $\begin{array}{c}6-31 G \\
(d, p)\end{array}$ & $\begin{array}{c}6-311+G \\
(2 d, p)\end{array}$ & \\
\hline \multicolumn{6}{|l|}{ Bond lengths } \\
\hline C1-C2 & 1.393 & 1.389 & 1.389 & 1.385 & 1.393 \\
\hline $\mathrm{C} 2-\mathrm{C} 3$ & 1.397 & 1.392 & 1.401 & 1.396 & 1.397 \\
\hline $\mathrm{C} 3-\mathrm{C} 4$ & 1.397 & 1.392 & 1.396 & 1.391 & 1.400 \\
\hline C4-C5 & 1.393 & 1.388 & 1.394 & 1.389 & 1.390 \\
\hline $\mathrm{C} 5-\mathrm{C} 6$ & 1.401 & 1.395 & 1.401 & 1.396 & 1.405 \\
\hline C1-C6 & 1.403 & 1.397 & 1.406 & 1.401 & 1.403 \\
\hline $\mathrm{C} 6-\mathrm{N}$ & 1.436 & 1.435 & 1.419 & 1.419 & 1.416 \\
\hline $\mathrm{N}=\mathrm{N}$ & 1.249 & 1.241 & 1.261 & 1.251 & 1.261 \\
\hline \multicolumn{6}{|l|}{ Bond angles } \\
\hline C2-C1-C6 & 119.6 & 119.6 & 119.6 & 119.6 & 120.2 \\
\hline C-C2-C & 120.5 & 120.4 & 120.4 & 120.5 & 119.7 \\
\hline C-C3-C & 119.8 & 119.7 & 120.0 & 120.0 & 120.2 \\
\hline C-C4-C & 120.1 & 120.2 & 119.8 & 119.9 & 120.4 \\
\hline C-C5-C & 120.0 & 119.9 & 120.2 & 120.2 & 119.6 \\
\hline C-C6-C & 119.9 & 120.0 & 119.9 & 120.0 & 119.9 \\
\hline C1-C6-N & 123.0 & 122.7 & 124.8 & 124.7 & 115.3 \\
\hline $\mathrm{C}-\mathrm{N}=\mathrm{N}$ & 124.0 & 124.1 & 114.8 & 115.4 & 115.8 \\
\hline \multicolumn{6}{|l|}{ Torsion angles } \\
\hline $\mathrm{C} 1-\mathrm{C} 2-\mathrm{C} 3-\mathrm{C} 4$ & -1.5 & -1.6 & 0.0 & 0.0 & -0.2 \\
\hline $\mathrm{C} 6-\mathrm{C} 1-\mathrm{C} 2-\mathrm{C} 3$ & 0.8 & 0.9 & 0.0 & 0.0 & 0.7 \\
\hline $\mathrm{C} 2-\mathrm{C} 1-\mathrm{C} 6-\mathrm{N}$ & 172.1 & 172.4 & 180.0 & 180.0 & -179.0 \\
\hline $\mathrm{C} 1-\mathrm{C} 6-\mathrm{N}=\mathrm{N}$ & 50.5 & 52.1 & 0.0 & 0.0 & -170.6 \\
\hline $\mathrm{C} 6-\mathrm{N}=\mathrm{N}-\mathrm{C}$ & 9.8 & 9.1 & 0.0 & 0.0 & -176.4 \\
\hline
\end{tabular}

However, in the cis orientation, there is a strong repulsion of both the rings. Thus, the structure is not planar, with one ring being almost perpendicular to the other. The repulsion is so strong that the atoms of both benzene rings appear with slight out-of-planarity (Table 1). It is noted that the torsional angles of the ring appear to be more easily deformed by this repulsion than the CCC angles, which are very close to those in the trans orientation. The $\mathrm{C} 1-\mathrm{C} 2$ and $\mathrm{C} 4-\mathrm{C} 5$ bond lengths are also shorter than the remaining $\mathrm{C}-\mathrm{C}$ bonds; however, the difference is very small e.g. the aromaticity of the benzene ring is very small. The nitrogen atom withdraws less negative charge on C6 e.g. the $\mathrm{C}-\mathrm{N}$ length appears to be longer than that in the trans form: $1.435 \AA$ vs. $1.419 \AA$ for the trans form. Because of this lengthening, the nitrogen atoms can be more strongly bonded: $1.241 \AA$ vs. $1.251 \AA$ for the trans form. All these features indicate the high flexibility of the molecule. Because of the asymmetry of the structure, the dipole moment is markedly increased, by up to $3.215 \mathrm{D}$, from the trans $\rightarrow$ cis isomerization (Table 3).

\section{PMMA Films}

We also simulated the interaction of trans-AZ in PMMA films using a simplified model with two sets of PMMA

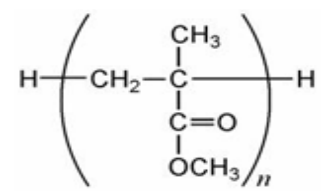

$(n=5)$ (Figure 1b) and its full optimization.

Only two very weak $\mathrm{C}-\mathrm{H} \cdots \mathrm{O} \mathrm{H}$-bonds and a $\mathrm{C}-\mathrm{H} \cdots \mathrm{N}$ interaction appear between PMMA and AZ, leading to the rotation of both benzene ring planes to an angle of $37.6^{\circ}$. The effect of PMMA in the bond lengths of $\mathbf{A Z}$ is small, with changes lower than $0.005 \AA$. However, it is very large in the $\mathrm{C} 1-\mathrm{C} 6-\mathrm{N}$ angle (Table 1).

\section{Wavenumber Calculation of AZ Molecule}

The $\mathbf{A Z}$ molecules and their derivatives have been the subject of many experimental studies using IR and 


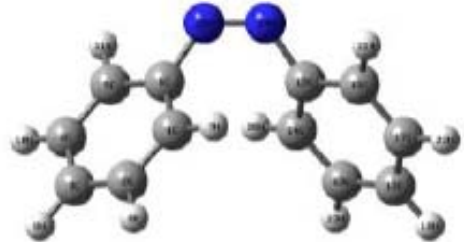

Cis

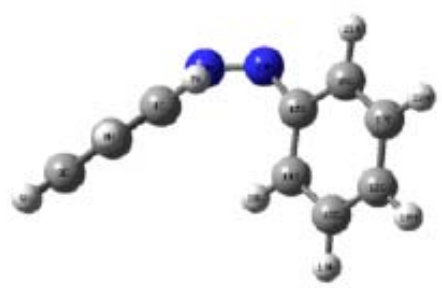

(a)

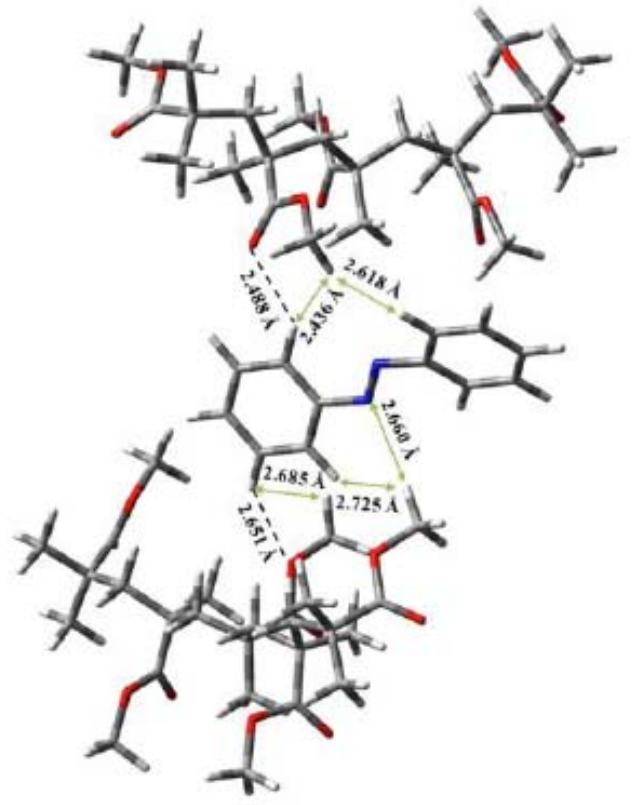

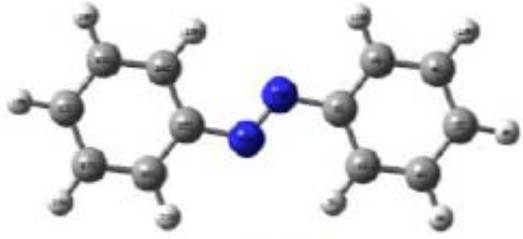

Trans

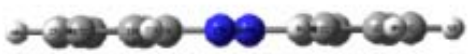

(b)

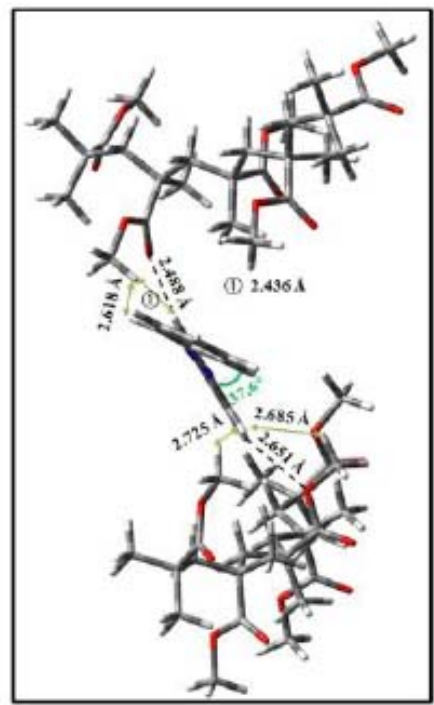

Figure 1: (a) Top and side views of optimized molecular structures of cis- and trans-AZ. (b) Top and side views of optimized molecular system of trans-AZ and two sets in PMMA $(n=5)$.

Table 2: Calculated Natural NBO Atomic Charges with the B3LYP Method in AZ

\begin{tabular}{|c|c|c|c|c|}
\hline \multirow{2}{*}{ Atom } & \multicolumn{2}{|c|}{ cis } & \multicolumn{2}{|c|}{ trans } \\
\cline { 2 - 5 } & $\begin{array}{c}\mathbf{6 - 3 1 G} \\
\mathbf{( d , p )}\end{array}$ & $\begin{array}{c}\mathbf{6 - 3 1 1 + G} \\
\mathbf{( 2 d , p )}\end{array}$ & $\begin{array}{c}\mathbf{6 - 3 1 G} \\
\mathbf{( d , p )}\end{array}$ & $\begin{array}{c}\mathbf{6 - 3 1 1 + G} \\
\mathbf{( 2 d , p )}\end{array}$ \\
\hline \hline C1 & -0.242 & -0.209 & -0.223 & -0.189 \\
C2 & -0.231 & -0.192 & -0.237 & -0.199 \\
C3 & -0.236 & -0.202 & -0.222 & -0.185 \\
C4 & -0.233 & -0.195 & -0.242 & -0.206 \\
C5 & -0.233 & -0.200 & -0.211 & -0.173 \\
C6 & 0.069 & 0.077 & 0.097 & -0.093 \\
N & -0.128 & -0.138 & -0.197 & -0.205 \\
\hline
\end{tabular}


Table 3: Theoretical Computed Total Energies and Gibbs Free Energy (A.U.), Rotational Constants (GHz), Entropies $\left(\mathrm{cal} \cdot \mathrm{mol}^{-1} \cdot \mathrm{K}^{-1}\right)$ and Dipole Moments (Debyes) at the B3LYP Level in AZ Molecule

\begin{tabular}{|c|c|c|c|c|c|}
\hline \multirow{2}{*}{ Parameters } & \multicolumn{2}{|c|}{ cis } & \multicolumn{2}{|c|}{ trans } & Trans in PMMA \\
\cline { 2 - 6 } & $\begin{array}{c}\mathbf{6 - 3 1 G} \\
\mathbf{( d , p )}\end{array}$ & $\begin{array}{c}\mathbf{6 - 3 1 1 + G} \\
\mathbf{( 2 d , p )}\end{array}$ & $\begin{array}{c}\mathbf{6 - 3 1 G} \\
\mathbf{( d , p )}\end{array}$ & $\begin{array}{c}\mathbf{6 - 3 1 1 + G} \\
\mathbf{( 2 d , p )}\end{array}$ & $\begin{array}{c}\mathbf{6 - 3 1 G} \\
\mathbf{( d , p )}\end{array}$ \\
\hline \hline & & & & & \\
Total energy+ZPE & $.563267^{\mathrm{a}}$ & $.709860^{\mathrm{a}}$ & $.585832^{\mathrm{a}}$ & $.733520^{\mathrm{a}}$ & $.006332^{\mathrm{b}}$ \\
Gibbs Free energy & $.601152^{\mathrm{a}}$ & $.747804^{\mathrm{a}}$ & $.625272^{\mathrm{a}}$ & $.772352^{\mathrm{a}}$ & \\
Rotational constants & 1.446 & 1.438 & 2.733 & 2.753 & 0.023 \\
& 0.455 & 0.460 & 0.292 & 0.292 & 0.009 \\
Entropy & 0.408 & 0.414 & 0.264 & 0.264 & \\
Total & & & & & \\
Translational & 104.4 & 104.6 & 105.7 & 106.7 & \\
Rotational & 41.5 & 41.5 & 41.5 & 41.5 & \\
Vibrational & 31.5 & 31.4 & 31.7 & 31.7 & \\
Dipole moments & 31.5 & 31.7 & 32.5 & 33.5 & \\
& 3.197 & 3.215 & 0.0 & 0.0 & 12.315 \\
\hline
\end{tabular}

${ }^{\mathrm{a}}-572 .{ }^{\mathrm{b}}-4112$.

Raman spectroscopic techniques [54, 57-60]. However, they have not been as accurately assigned as in the present study (Table S1). Moreover, we have reassigned several bands. In addition, the analysis of AZ in PMMA films has not yet been reported; thus, we present a discussion of such an analysis. The simulation of the vibrational spectra is based on DFT calculations and accurate scaling.

The calculated wave numbers in the $\mathbf{A Z}$ molecule were improved using the linear scaling equation procedure (LSEP). For this purpose, a scaling equation was determined in the benzene molecule at the same level as that in the $\mathbf{A Z}$ :

$$
\begin{aligned}
v^{\text {scaled }}= & 22.1+0.9543 \cdot \omega^{\text {calculated }} \\
& (B 3 L Y P / 6-31 G(d, p))
\end{aligned}
$$

Figures 2 and $\mathbf{3}$ show the simulated scaled IR spectra. Other scaling procedures can be performed, but they appear less accurate than LSEP [48, 49]. Table $\mathbf{S 1}$ gives the theoretical and scaled wavenumbers obtained by IR and Raman (calculated for comparison) spectroscopy for the trans form, while Table $\mathbf{S 2}$ refers to the cis form. The first column lists, in increasing order, the calculated wavenumbers at the B3LYP/6-31G(d,p) level, while the second column shows their respective relative (\%) IR intensities (A), and the third column shows their relative Raman scattering activities (S). The relative IR and Raman intensities were obtained by normalizing the computed values to the intensity of the strongest line. The fourth to tenth columns show the calculated values at the B3LYP/6-311+G(2d,p) level. The reduced masses $(\mu)$ (seventh column), force constant of each vibration ( $f$ ) (eighth column), Raman depolarization ratios for plane (P) (ninth column), and unpolarized incident light (U) (tenth column) are also shown. Columns 11 and 12 correspond to the scaled values from the scaling equation with the two basis sets. Two wavenumbers have been characterized from each ring mode corresponding to the two phenyl rings (with the exception of modes 1 and 10b). These values can be directly compared to the experimental IR bands. In the last column, the characterization for each calculated wavenumber determined in the ring and substituent modes is shown. Assignment of the ring modes followed the Varsanyi notation [61] for a monosubstituted benzene.

For our simulated model, analysis and assignment of the computed values of $\mathbf{A Z}$ in PMMA films were also performed. Table $\mathbf{S 1}$ shows the vibrations corresponding to $\mathbf{A Z}$ in this system. These were identified from the 546 frequencies calculated for the system. The simulated scaled IR spectrum with these frequencies is included in Figures 2 and 3, in addition to others in which there appears to be a noticeable \% contribution of the modes of $\mathbf{A Z}$. The last column of Table $\mathbf{S 1}$ shows the calculated frequency shift of $\mathbf{A Z}$ in the simulated PMMA film. As observed, few modes appear to be coupled between AZ and PMMA i.e. the interaction between them is weak and has little influence on the frequency values.

\section{Metal Complexes (with AZ in PMMA Films)}

Electron-withdrawing $\mathrm{Br}$ atoms are bonded as substituents in two phenyl rings. Figures 4-6 show the 

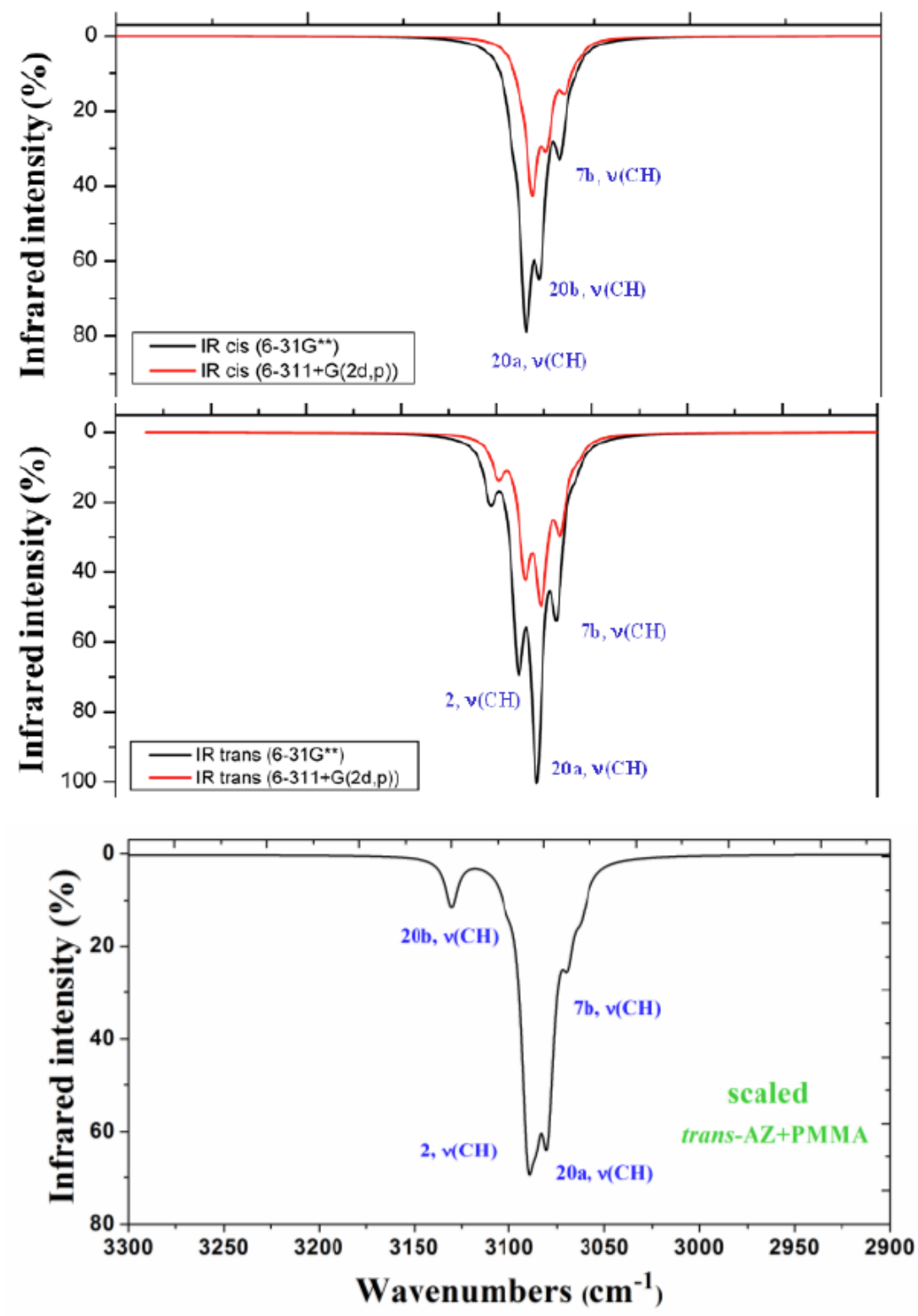

Figure 2: Theoretical scaled IR spectra in the $3300-2900 \mathrm{~cm}^{-1}$ range in the cis and trans isomers and at the $B 3 \mathrm{LYP} / 6-31 \mathrm{G}(\mathrm{d}, \mathrm{p})$ and $B 3 L Y P / 6-311+G(2 d, p)$ levels using the scale equation procedure obtained from the benzene molecule and that simulated with trans-AZ in PMMA.

optimized structure obtained using the B3LYP, M052X, and M062X DFT methods and the 6-31G(d,p) basis set. Conformer 1 corresponds to the most stable case, although the difference in energy is very small in the $\mathbf{~ N i}$ complex $\left(0.98 \mathrm{kcal} \mathrm{mol}^{-1}\right.$ with B3LYP) and high in the Cu complex $\left(2.83 \mathrm{kcal} \mathrm{mol}^{-1}\right)$. In these structures, all the phenyl rings are out-of-planarity to avoid steric interactions. The calculated wavenumbers were scaled following LSEP equations:

$$
\begin{aligned}
& v^{\text {scaled }}=22.1+0.9543 \cdot \omega^{\text {calculated }}(B 3 L Y P / 6-31 G(d, p)) \\
& v^{\text {scaled }}=24.5+0.9366 \cdot \omega^{\text {calculated }}(M 052 X / 6-31 G(d, p)) \\
& v^{\text {scaled }}=22.7+0.9417 \cdot \omega^{\text {calculated }}(M 062 X / 6-31 G(d, p))
\end{aligned}
$$

The experimental and scaled IR spectra are shown in Figures S6-S8. Because of the IR intensity depending of many factors not considered in the theory, this comparison must be performed on the frequency values. A summary of the most intense IR bands is provided in Tables S3-S5. In general, the scaled wavenumbers appear very close to the experimental data, with errors less than $2 \%$. Moreover, the three DFT methods show similar results i.e. the simulated structure and the assignment seem to be correct. Small differences are observed in the experimental IR spectra of the complexes with $\mathbf{N i}, \mathbf{C u}$, and $\mathbf{Z n}$ e.g. the influence of the metal in the structure of each individual fragment is small. The differences 

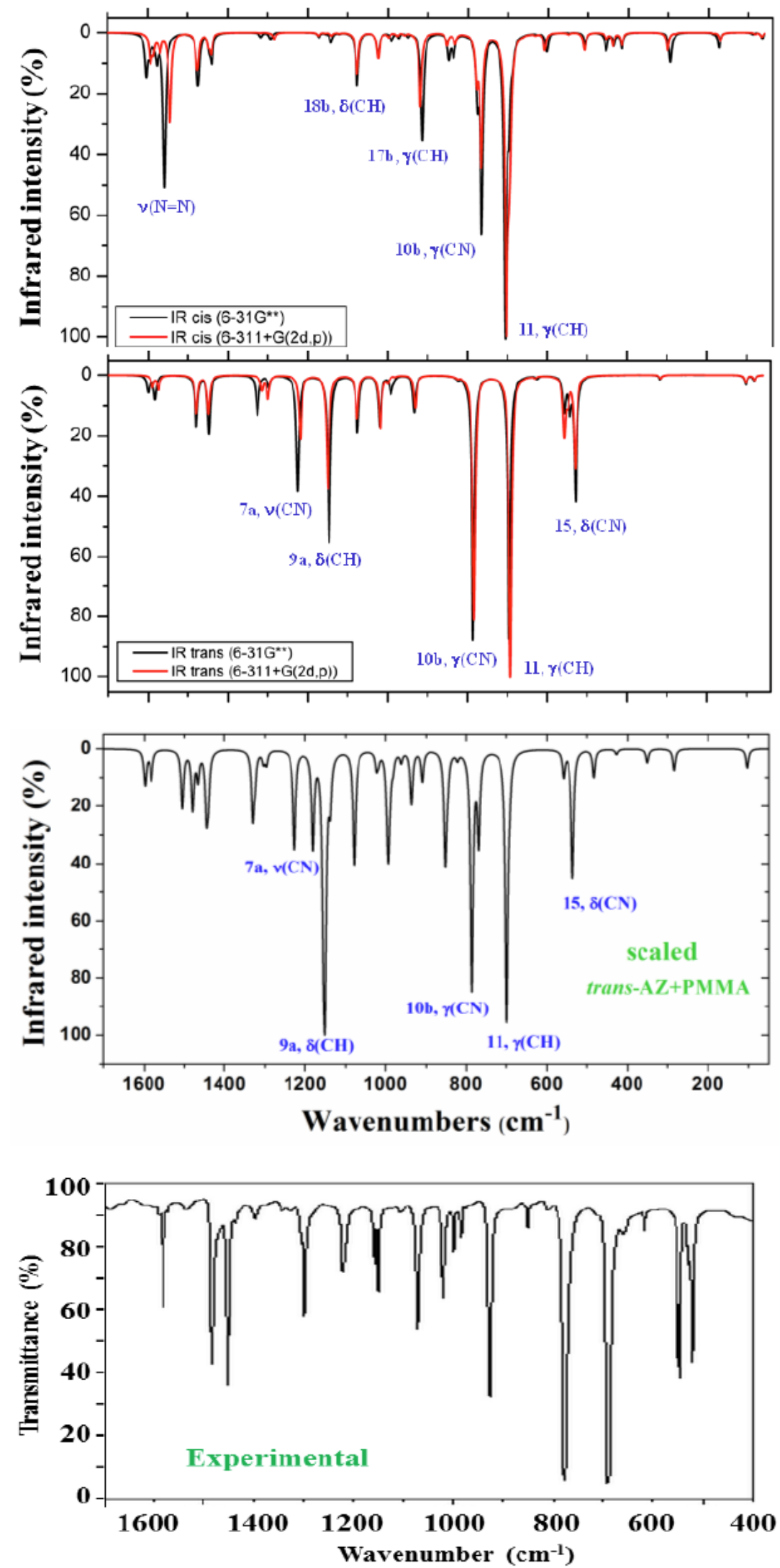

Figure 3: Theoretical scaled IR spectrum in the $1700-50 \mathrm{~cm}^{-1}$ range using the scale equation procedure from the benzene molecule and experimental IR spectra in the $1700-400 \mathrm{~cm}^{-1}$ range. 


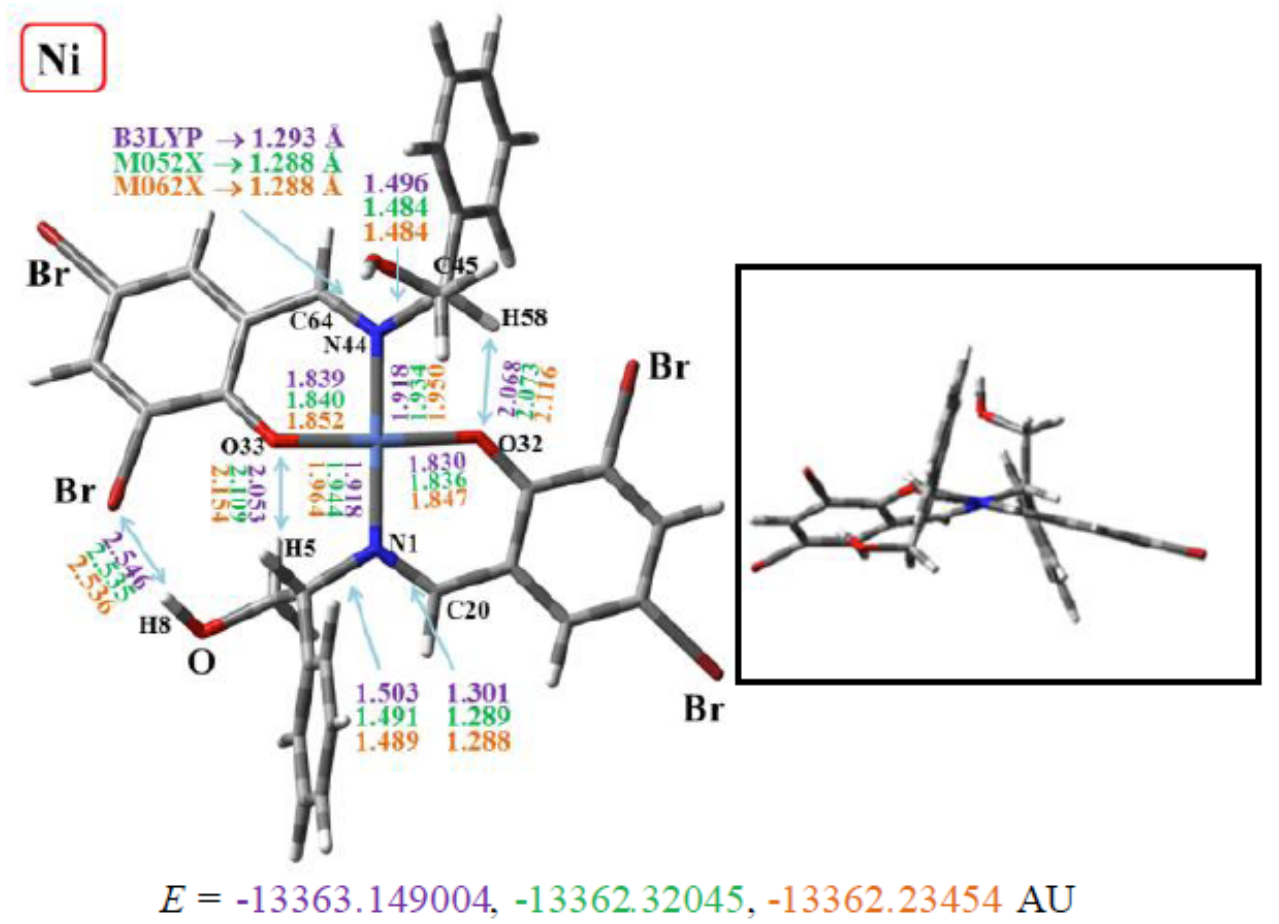

Figure 4: Two views of the optimized molecular structure with the B3LYP, M052X, and M062X DFT methods in conformer 1 of the azobenzene complex with $\mathbf{N i}$. All the bond lengths values are in $\AA$. At the bottom is the total energy of the complex (+ ZPE) in $\mathrm{AU}$.

observed experimentally are markedly smaller than those determined theoretically in the isolated state, indicating that the Nujol solution perhaps reduces the molecular flexibility and special distribution of the fragments in these complexes to a simpler form. Only the spectrum of the complex with $\mathbf{Z n}$ shows some significant difference. This is confirmed by the similar wavenumber observed for the $v(\mathrm{C}-\mathrm{N})$ mode, corresponding to the complexes with $\mathrm{Ni}\left(1629 \mathrm{~cm}^{-1}\right)$, $\mathrm{Cu}\left(1628 \mathrm{~cm}^{-1}\right)$, and $\mathbf{Z n}\left(1610 \mathrm{~cm}^{-1}\right)$.

With regard to the molecular structure of the $\mathbf{N i}$ complex (Figures 4 and S3), all the carbon and nitrogen atoms bonded to the $\mathrm{Ni}$ atom are in-plane, with values of $\mathrm{O}-\mathrm{Ni}-\mathrm{O}=177.4^{\circ}$ and $\mathrm{N}-\mathrm{Ni}-\mathrm{N}=178.9^{\circ}$ Contributing to the asymmetry of the molecule are three weak contacts/H-bonds: $\mathrm{H} 8 \cdots \mathrm{Br}(2.546 \AA$ with

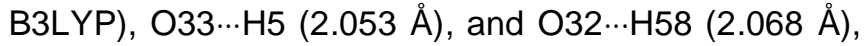
observed as a violet color at the B3LYP/6-31G(d,p) level in Figure 4. Consequently, the $\mathrm{O} 33-\mathrm{Ni}$ bond is slightly shorter than the O32-Ni bond, and the N44-Ni bond is slightly longer than the $\mathrm{N} 1-\mathrm{Ni}$ bond. In the middle IR spectrum, the bands with the highest intensity correspond to $\mathrm{C}-\mathrm{N}$ stretching. The shortest bonds are $\mathrm{C}=\mathrm{N}$, and these correspond to $\mathrm{C64}-\mathrm{N} 44$

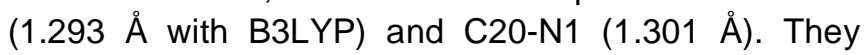
have calculated wavenumbers at $1684 \mathrm{~cm}^{-1}$ (scaled at $1629 \mathrm{~cm}^{-1}$ ) and at $1669 \mathrm{~cm}^{-1}$ (scaled at $1615 \mathrm{~cm}^{-1}$ ), respectively, and very strong IR intensity in accordance with the experimental band, showing strong intensity at $1629 \mathrm{~cm}^{-1}$. The bands corresponding to C45-N44 and C2-N1 appear at lower wavenumbers (in accordance with their longer bond lengths) and with weak IR intensity.

In the Cu complex (Figure 5), the carbon and nitrogen atoms bonded to the $\mathrm{Cu}$ atom are not in-plane, with values of $\mathrm{O}-\mathrm{Cu}-\mathrm{O}=154.7^{\circ}$ and $\mathrm{N}-\mathrm{Cu}-\mathrm{N}=152.9^{\circ}$ with B3LYP. Similar values were obtained by M052X and M062X. Similar to the Ni complex, this molecule is asymmetric with three weak contacts, as shown in Figure 5. It should be noted that the removal of one hydrogen atom was necessary (Figure 5 ) to produce a stable structure. The $v(\mathrm{C}=\mathrm{N})$ stretchings are predicted with very strong IR intensity at $1851 \mathrm{~cm}^{-1}$ (scaled at $1788 \mathrm{~cm}^{-1}$ ) and at $1676 \mathrm{~cm}^{-1}$ (scaled at $1621 \mathrm{~cm}^{-1}$ ) by B3LYP. This is also in very good accordance with the M052X and M062X values and with the experimental band detected at $1628 \mathrm{~cm}^{-1}$.

The $\mathbf{Z n}$ complex shows the greatest degree of outof-planarity of the carbon and nitrogen atoms bonded to the $\mathrm{Zn}$ atom, with values of $\mathrm{O}-\mathrm{Zn}-\mathrm{O}=133.4^{\circ}$ and $\mathrm{N}$ $\mathrm{Zn}-\mathrm{N}=136.7^{\circ}$ by B3LYP. This molecule is also stabilized by weak contacts, as shown in Figure 6 . In the middle IR-spectrum, the bands with the highest IR 


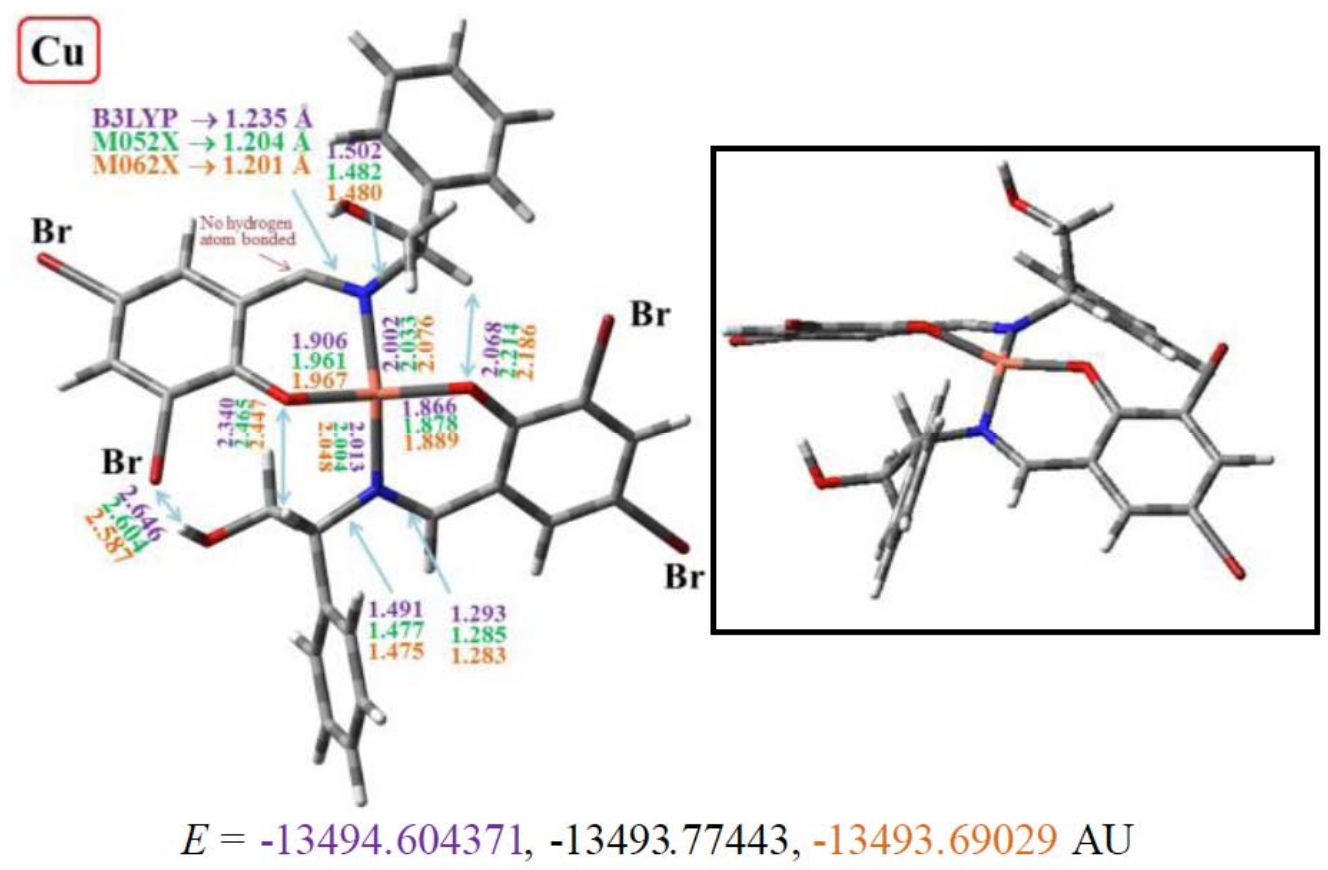

Figure 5: Two views of the optimized molecular structure with the B3LYP, M052X, and M062X DFT methods in conformer 1 of the azobenzene complex with $\mathbf{C u}$.

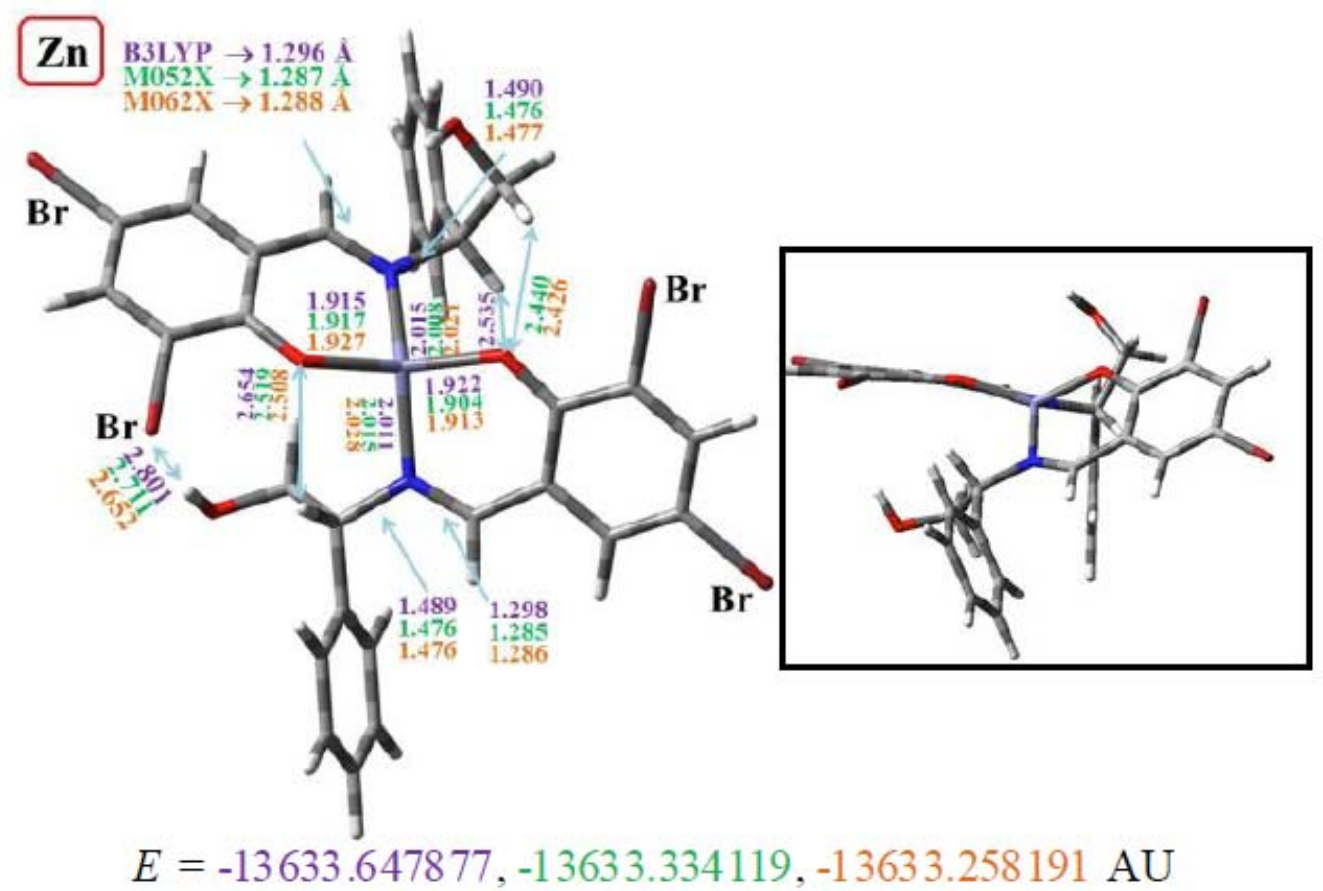

Figure 6: Two views of the optimized molecular structure with the B3LYP, M052X, and M062X DFT methods in conformer 1 of the azobenzene complex with $\mathbf{Z n}$.

intensity also correspond with the $v(\mathrm{C}=\mathrm{N})$ stretchings calculated at $1680 \mathrm{~cm}^{-1}$ (scaled at $1625 \mathrm{~cm}^{-1}$ ) and at $1667 \mathrm{~cm}^{-1}$ (scaled at $1613 \mathrm{~cm}^{-1}$ ). They are also in very good accordance with the M052X and M062X values and with the weak band observed in the experimental spectrum at $1610 \mathrm{~cm}^{-1}$.
Through the analysis of the molecular structure of these complexes in the isolated state, we have not observed any particular difference that would give rise to a flexible structure for $\mathbf{N i}$ and $\mathbf{C u}$ and a rigid complex for $\mathbf{Z n}$. The only special characteristic of the $\mathbf{Z n}$ complex is the high out-of-planarity of the structure. 
Perhaps, this out-of-planarity leads to high molecular interactions ( $\mathrm{H}$-bonds) with neighboring molecules, leading to a rigid complex. This complex with $\mathrm{Zn}$ is also more open, with a larger $\mathrm{Br} 30 \ldots \mathrm{Br} 43$ distance $(14.8 \AA$ by $B 3 L Y P)$ than that in the Ni complex $(14.4 \AA)$ and in the Cu complex (13.9 $\AA$ ).

Low-lying molecular vibrations have been studied by several authors [63-65], and their presence indicates a high flexibility in the molecular structure, which may be caused by various factors. Twenty-nine frequencies below $200 \mathrm{~cm}^{-1}$ were found in the complex with $\mathbf{C u}$, corroborating its high flexibility, while in the complex with $\mathbf{Z n}, 28$ were found and in the complex with $\mathbf{N i}, 26$ were found. A first group of these vibrations includes those that represent the motion of the different rings with respect to each other as almost rigid subsystems, while a second group involves their intramolecular deformation.

\section{Linearly Polarized UV Light-Induced Optical Anisotropy}

Figure 7 shows polarized UV-vis spectra before and after linearly polarized UV light irradiation for $10 \mathrm{~min}$ at $45^{\circ}$ and circular diagrams of the angular dependence of absorbance at $\pi-\pi^{*}(318 \mathrm{~nm}), \mathrm{n}-\pi^{*}(440 \mathrm{~nm})$, and $d-$ $\mathrm{d}$ bands in polarized UV-vis spectra before and after linearly polarized UV light irradiation $(0.5,1,3,5$, and $10 \mathrm{~min}$ ). At the $\mathrm{d}-\mathrm{d}$ band (Ni: $595 \mathrm{~nm}, \mathbf{C u}: 625 \mathrm{~nm}$ ), increases in optical anisotropy were observed. These results suggest that both $\mathbf{A Z}$ and the complexes were oriented by linearly polarized UV light irradiation.

Tables 4 and 5 summarize optical anisotropic parameters ( $R$ and $S$ values) of the hybrid materials $\mathbf{N i}$ $+\mathbf{A Z}+$ PMMA, Cu + AZ + PMMA, and $\mathbf{Z n}+\mathbf{A Z}+$ PMMA. To allow for discussion of the Weigert effect, the degree of photo-induced optical anisotropy (in other words, spectral dichroism) of polarized UV-vis spectra can be commonly described by two parameters:

$$
\begin{gathered}
S=\left(A_{\text {parrallel }}-A_{\text {perpendicular }} /\left(2 A_{\text {perpendicular }}+A_{\text {parrallel }}\right)\right. \\
R=A_{\text {perpendicular }} / A_{\text {parrallel }}
\end{gathered}
$$

where $A_{\text {perpendicular and }} A_{\text {parrallel }}$ values denote absorbance measured with the polarizer perpendicular or parallel, respectively, to the electric vector of irradiation polarized light. The ideal isotropic systems of $S=0$ and $R=1$, and both $S$ and $R$ parameters, are changed with increasing dichroism by molecular alignment.
Assignment of spectral peaks was in agreement with the analogous compounds [26, 28, 38, 39]. As listed in Tables $\mathbf{4}$ and $\mathbf{5}$, the $\pi-\pi^{*}$ and $n-\pi^{*}$ bands of $\mathbf{A Z}$ were directly changed by the Weigert effect, while the $\mathrm{d}-\mathrm{d}$ bands of $\mathbf{N i}$ or $\mathrm{Cu}$ were changed by supramolecular interaction in the PMMA matrix. However, $\mathbf{Z n}$ did not exhibit $d-d$ bands because of $d^{10}$ configuration of the $\mathrm{Zn}$ (II) center [22].

In the PMMA hybrid materials, the 10-min $R$ values due to the $\mathrm{d}$ - $\mathrm{d}$ bands of $\mathbf{N i}$ and $\mathrm{Cu}$ are 5.6838 and 1.5286 for $\mathbf{N i}+\mathbf{A Z}+$ PMMA and $\mathbf{C u}+\mathbf{A Z}+\mathbf{P M M A}$, respectively. Focusing on the common $\pi-\pi^{*}$ bands of $\mathbf{A Z}$ around $318 \mathrm{~nm}$, the 10-min $\mathrm{R}$ values are 1.0139, 1.0037, and 0.9338 for $\mathbf{N i}, \mathbf{C u}$, and $\mathbf{Z n}+\mathbf{A Z}+\mathbf{P M M A}$, respectively. According to Table $\mathbf{6}$, the degree of freedom may be caused by intermolecular interaction of non-contacted molecules of $\mathbf{A Z}$ and $\mathbf{N i}, \mathbf{C u}$, or $\mathbf{Z n}$. Similar behavior was observed for the $S$ values, as summarized in Table 5. In general, looseness of data is mainly attributed to $\mathbf{A Z}$ degradation [23].

To allow for selective observation of contained components (AZ or complexes) in hybrid materials (in other words, direct proof of supramolecular interaction from the Weigert effect to the optical anisotropy of complexes), polarized IR spectra (Figure 8) were measured, in which $\mathrm{C}=\mathrm{N}$ bands of metal complexes were used as a probe to detect each component separately. Tables 6 and 7 summarize the optical anisotropic $R$ and $S$ values from the polarized $I R$ spectra of the hybrid materials $\mathbf{N i}+\mathbf{A Z}+\mathbf{P M M A}, \mathbf{C u}+$ $\mathbf{A Z}+\mathbf{P M M A}$, and $\mathbf{Z n}+\mathbf{A Z}+\mathbf{P M M A}$ after linearly polarized UV light irradiation. The $10-\mathrm{min} R$ values due to $\mathrm{C}=\mathrm{N}$ bands of $\mathrm{Ni}\left(1629 \mathrm{~cm}^{-1}\right), \mathrm{Cu}\left(1628 \mathrm{~cm}^{-1}\right)$, and $\mathbf{Z n}\left(1610 \mathrm{~cm}^{-1}\right)$ are $1.1770,1.0058$, and 1.0509 for $\mathbf{N i}+$ $A Z+P M M A, C u+A Z+P M M A$, and $Z n+A Z+$ PMMA, respectively.

The $R$ and $S$ values at the $\pi-\pi^{*}$ bands of the polarized UV-vis spectra provided information on molecular orientation and conformation. Meanwhile, the $R$ and $S$ values at the $d-d$ band of the polarized UV-vis spectra and the $\mathrm{C}=\mathrm{N}$ bands of the polarized IR spectra provide information such as the coordination environment. Tables 4 and 6 indicate the following mechanism. Increases in optical anisotropy after linear UV light irradiation for $10 \mathrm{~min}$ followed the following order: $\mathbf{Z n}+\mathbf{A Z}+\mathbf{P M M A}>\mathbf{N i}+\mathbf{A Z}+\mathbf{P M M A}>\mathbf{C u}+\mathbf{A Z}$ + PMMA at $\pi-\pi^{*}, \mathrm{Ni}+\mathrm{AZ}+\mathrm{PMMA}>\mathrm{Cu}+\mathrm{AZ}+$ PMMA $>\mathrm{Zn}+\mathrm{AZ}+\mathrm{PMMA}$ at $\mathrm{n}-\pi^{*}$, and $\mathrm{Ni}+\mathbf{A Z}+$ PMMA $>\mathrm{Cu}+\mathbf{A Z}+$ PMMA at $d$-d. The reason for maximum $\pi-\pi^{*}$ values for $\mathbf{Z n}+\mathbf{A Z}+\mathbf{P M M A}$ may be 


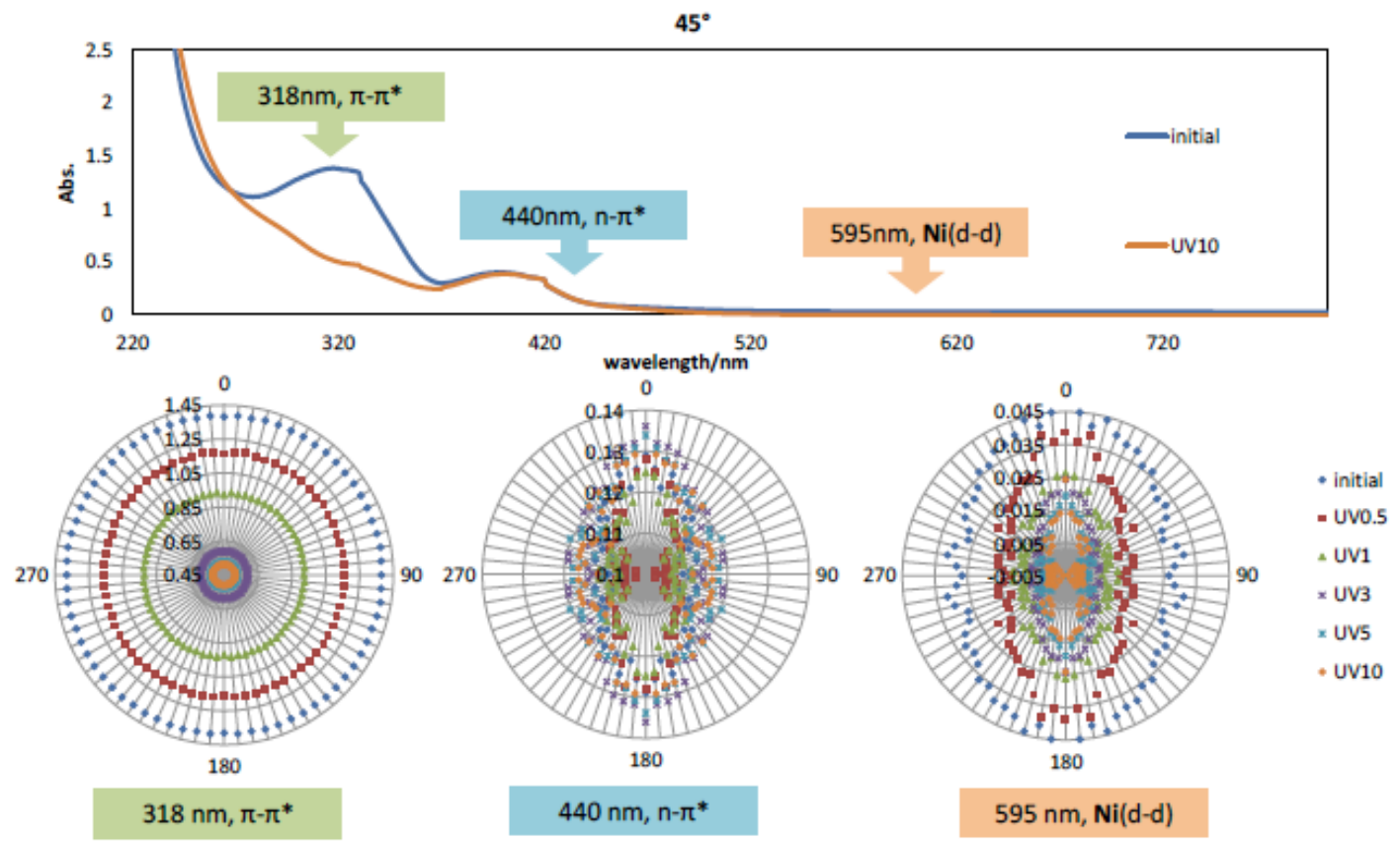

Figure 7: Polarized UV-vis spectra at $45^{\circ}$ [above] and angular dependence of absorbance at 318,440 , and $595 \mathrm{~nm}$ [below] for $\mathbf{N i}+\mathbf{A Z}+$ PMMA after linearly polarized UV light irradiation for 0-10 min.

that distorted Zn become to exhibit small contribution and mainly observed intense absorption from orientated $\mathbf{A Z}$. The order of $\mathrm{C}=\mathrm{N}$ (complexes) and $\mathrm{N}=\mathrm{N}$ $(\mathbf{A Z})$ bands from the polarized IR spectra is $\mathbf{N i}+\mathbf{A Z}+$ PMMA $>$ Zn + AZ + PMMA > Cu + AZ + PMMA. The results indicate that $\mathbf{N i}+\mathbf{A Z}+\mathbf{P M M A}$ may induce optical anisotropy most effectively. This also suggests that re-orientation of the complexes due to the Weigert effect of $\mathbf{A Z}$ depends on the flexibility of the coordination environment produced by the metal ions [28] and the overall planarity of the ligands or molecules.

\section{Interpretation of the Molecular Orientation}

According to our findings, we can examine the orientation of each molecule. Initially, we discuss the orientation of $\mathbf{A Z}$ on the basis of the results of the polarized UV-vis spectra. As shown in Figure 9, when linearly polarized UV light vibrating (having an electric vector) in the $0^{\circ}$ direction was irradiated onto the hybrid materials, the intensity of the $\pi-\pi^{*}$ band in the $90^{\circ}$ direction became stronger because of the Weigert effect, which is parallel to the transition dipole moment (long molecular axis) of cis-AZ [34, 38, 39]. Therefore, $\mathrm{N}=\mathrm{N}$ bonds of $\mathbf{A Z}$ are expected to be oriented perpendicular to the irradiated polarized light.

As shown in Figure 10, when polarized UV light vibrating in the $0^{\circ}$ direction was irradiated onto the hybrid materials, the IR intensity of the $\mathrm{N}=\mathrm{N}$ band in the $90^{\circ}$ direction became stronger because of an allowed transition, which is parallel to the transition dipole moment (long molecular axis) of cis-AZ. The $N=N$ bonds of cis-AZ are expected to be oriented parallel to the $90^{\circ}$ polarized IR by the vibration mode of the $\mathrm{N}=\mathrm{N}$ stretching vibration; this has been discussed on the basis of TD-DFT theoretical calculations.

Next, we discuss orientation of the complexes. Because the $\mathrm{C}=\mathrm{N}$ bond also has a strong absorption at $90^{\circ}$ in the polarized IR spectra, this bond is considered to be oriented parallel to $90^{\circ}$. In other words, the $\mathrm{C}=\mathrm{N}$ bond of complexes and $\mathrm{N}=\mathrm{N}$ bond of $\mathbf{A Z}$ are aligned in a parallel fashion after linearly polarized light irradiation (Figure 11).

Here we consider the driving force that leads to complexes becoming oriented. If complexes are directly oriented because of the Weigert effect by polarized UV light irradiation, the dipole moment of the complexes should be perpendicular to the irradiated polarized UV light (electric vector). According to the molecular shape (long molecular axis) of the complexes, the dipole moment of the complex must be vertical to the electric vector; in other words, the $\mathrm{C}=\mathrm{N}$ bonds of the complex are not parallel to the $\mathrm{N}=\mathrm{N}$ bond in AZ. Consequently, the mechanism of light-induced molecular orientation of the complexes was not directly because of the Weigert effect but because of supramolecular transmission from the re-orientation of AZ [33]. 
Table 4: The R Values from UV-vis Spectra after Linearly Polarized UV light irradiation

\begin{tabular}{|c|c|c|c|c|c|c|c|}
\hline \multicolumn{2}{|c|}{ UV radiation minutes } & initial & UV0.5 & UV1 & UV3 & UV5 & UV10 \\
\hline \multirow{3}{*}{$\begin{array}{c}\mathrm{Ni}+\mathrm{AZ}+ \\
\text { PMMA }\end{array}$} & $\begin{array}{c}318 \mathrm{~nm}, \\
\pi-\pi^{*}\end{array}$ & 1.0079 & 1.0134 & 1.0100 & 1.0075 & 1.0069 & 1.0139 \\
\hline & $\begin{array}{c}440 \mathrm{~nm} \\
\mathrm{n}-\pi^{*}\end{array}$ & 1.1817 & 1.2466 & 1.1736 & 1.2046 & 1.2056 & 1.2646 \\
\hline & $\begin{array}{l}595 \mathrm{~nm}, \\
\mathrm{~d}-\mathrm{d}(\mathrm{Ni})\end{array}$ & 1.8098 & 3.2780 & 4.1863 & -173.79 & -4.7056 & -5.6838 \\
\hline \multirow{3}{*}{$\begin{array}{c}\mathrm{Cu}+\mathrm{AZ+} \\
\text { PMMA }\end{array}$} & $\begin{array}{c}318 \mathrm{~nm}, \\
\pi-\pi^{*}\end{array}$ & 0.9775 & 1.0163 & 1.0154 & 1.0534 & 1.0247 & 1.0037 \\
\hline & $\begin{array}{c}440 \mathrm{~nm} \\
\mathrm{n}-\mathrm{m}^{*}\end{array}$ & 0.8465 & 1.2605 & 1.2092 & 1.2938 & 1.2207 & 1.2335 \\
\hline & $\begin{array}{l}625 \mathrm{~nm}, \\
\mathrm{~d}-\mathrm{d}(\mathbf{C u})\end{array}$ & 1.2043 & 1.4599 & 1.4123 & 1.6162 & 1.4930 & 1.5286 \\
\hline \multirow{2}{*}{$\begin{array}{c}\mathrm{Zn+AZ+} \\
\text { PMMA }\end{array}$} & $\begin{array}{c}318 \mathrm{~nm} \\
\pi-\pi^{*}\end{array}$ & 0.9499 & 0.9680 & 0.9706 & 0.9453 & 0.9439 & 0.9338 \\
\hline & $\begin{array}{c}440 \mathrm{~nm}, \\
\mathrm{n}-\pi^{*}\end{array}$ & 0.7825 & 1.1476 & 1.2053 & 1.1661 & 1.1658 & 1.1797 \\
\hline
\end{tabular}

Table 5: The S Values from UV-vis Spectra after Linearly Polarized UV Light Irradiation

\begin{tabular}{|c|c|c|c|c|c|c|c|}
\hline \multicolumn{2}{|c|}{ UV radiation minutes } & initial & UV0.5 & UV1 & UV3 & UV5 & UV10 \\
\hline \multirow{3}{*}{$\begin{array}{c}\mathrm{Ni}+\mathrm{AZ}+ \\
\text { PMMA }\end{array}$} & $\begin{array}{c}318 \mathrm{~nm}, \\
\pi-\pi^{*}\end{array}$ & 0.0026 & 0.0045 & 0.0033 & 0.0025 & 0.0023 & 0.0046 \\
\hline & $\begin{array}{c}440 \mathrm{~nm} \\
\mathrm{n}-\pi^{*}\end{array}$ & 0.0571 & 0.0760 & 0.0547 & 0.0638 & 0.0641 & 0.0811 \\
\hline & $\begin{array}{l}595 \mathrm{~nm}, \\
\text { d-d (Ni) }\end{array}$ & 0.2125 & 0.4316 & 0.5151 & 1.0175 & 2.1088 & 1.8144 \\
\hline \multirow{3}{*}{$\begin{array}{c}\mathrm{Cu}+\mathrm{AZ+} \\
\text { PMMA }\end{array}$} & $\begin{array}{c}318 \mathrm{~nm} \\
\pi-\pi^{*}\end{array}$ & -0.0075 & 0.0054 & 0.0051 & 0.0175 & 0.0082 & 0.0012 \\
\hline & $\begin{array}{c}440 \mathrm{~nm} \\
n-\pi^{*}\end{array}$ & -0.0539 & 0.0799 & 0.0652 & 0.0892 & 0.0685 & 0.0722 \\
\hline & $\begin{array}{l}625 \mathrm{~nm}, \\
\mathrm{~d}-\mathrm{d}(\mathrm{Cu})\end{array}$ & 0.0637 & 0.1329 & 0.1208 & 0.1704 & 0.1411 & 0.1498 \\
\hline $\begin{array}{c}\mathrm{Zn+AZ+} \\
\text { PMMA }\end{array}$ & $\begin{array}{c}440 \mathrm{~nm} \\
\mathrm{n}-\pi^{*}\end{array}$ & -0.0782 & 0.0469 & 0.0640 & 0.0525 & 0.0524 & 0.0565 \\
\hline
\end{tabular}

Table 6: The R Values from IR Spectra after Linearly Polarized UV Light Irradiation

\begin{tabular}{|c|c|c|c|c|c|c|c|}
\hline \multicolumn{2}{|c|}{ UV radiation minutes } & initial & UV0.5 & UV1 & UV3 & UV5 & UV10 \\
\hline $\begin{array}{c}\mathrm{Ni}+\mathrm{AZ}+ \\
\text { PMMA }\end{array}$ & $\begin{array}{c}1629 \mathrm{~cm}^{-1} \\
\mathrm{C}=\mathrm{N}(\mathbf{N i})\end{array}$ & 1.0079 & 1.0134 & 1.0100 & 1.0075 & 1.0069 & 1.0139 \\
\hline $\begin{array}{c}\mathrm{Cu}+\mathrm{AZ}+ \\
\text { PMMA }\end{array}$ & $\begin{array}{l}1628 \mathrm{~cm}^{-1} \\
\mathrm{C}=\mathrm{N}(\mathbf{C u})\end{array}$ & 0.9775 & 1.0163 & 1.0154 & 1.0534 & 1.0247 & 1.0037 \\
\hline $\begin{array}{c}\mathrm{Zn+AZ+} \\
\text { PMMA }\end{array}$ & $\begin{array}{l}1610 \mathrm{~cm}^{-1} \\
\mathrm{C}=\mathrm{N}(\mathrm{Zn})\end{array}$ & 0.9499 & 0.9680 & 0.9706 & 0.9453 & 0.9439 & 0.9338 \\
\hline
\end{tabular}



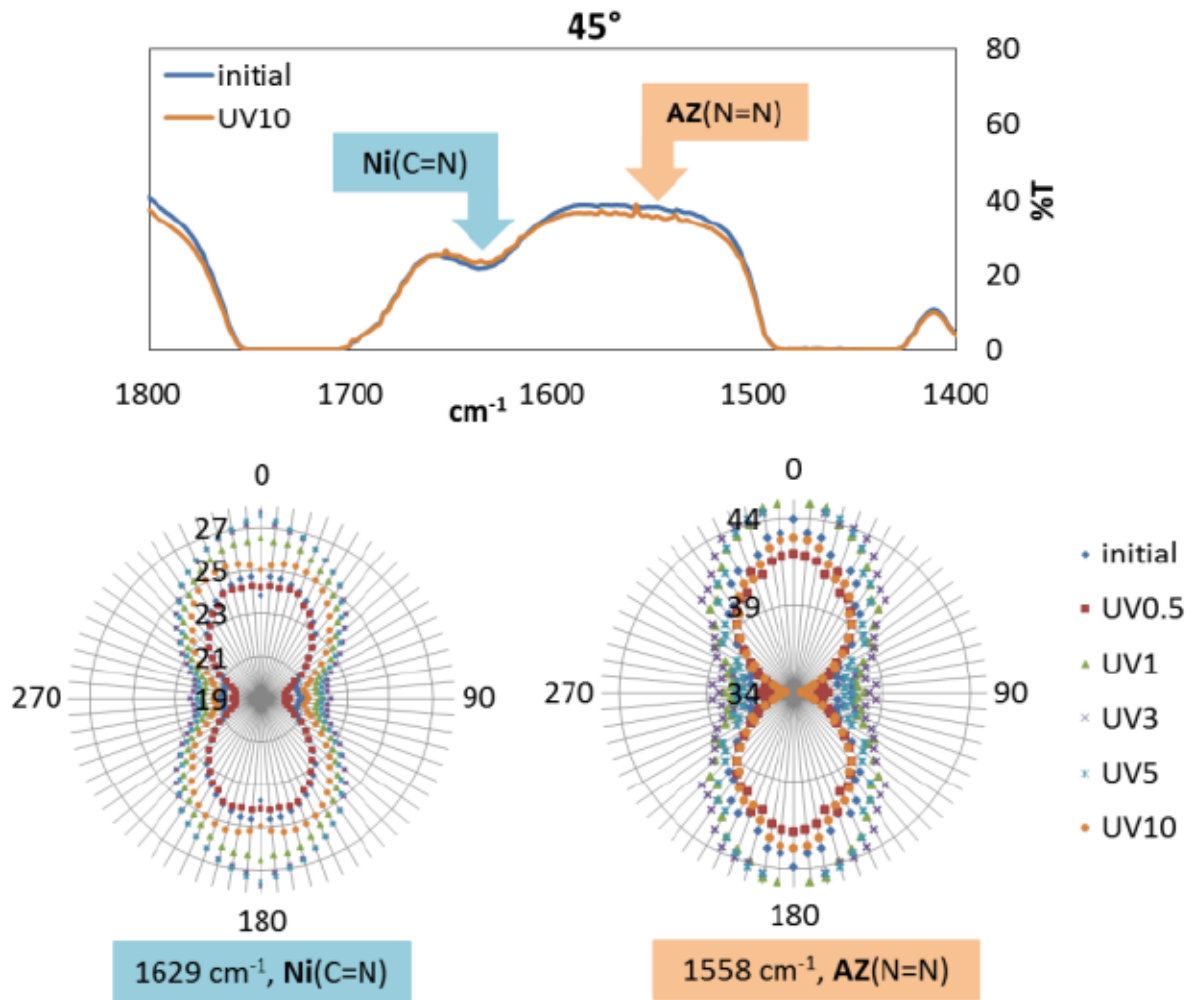

Figure 8: Polarized IR spectra at $45^{\circ}$ [above] and angular dependence of transmittance at $1629 \mathrm{~cm}^{-1}(\mathrm{C}=\mathrm{N})$ and $1558 \mathrm{~cm}^{-1}$ $(\mathrm{N}=\mathrm{N})$ [below] for $\mathbf{N i}+\mathbf{A Z}+\mathbf{P M M A}$ after linearly polarized UV light irradiation for 0-10 min.

Table 7: The S Values from IR Spectra after Linearly Polarized UV Light Irradiation

\begin{tabular}{|c|c|c|c|c|c|c|c|}
\hline \multicolumn{2}{|c|}{ UV radiation minutes } & initial & UV0.5 & UV1 & UV3 & UV5 & UV10 \\
\hline $\begin{array}{c}\mathrm{Ni}+\mathrm{AZ}+ \\
\text { PMMA }\end{array}$ & $\begin{array}{c}1629 \mathrm{~cm}^{-1} \\
\mathrm{C}=\mathrm{N}(\mathrm{Ni})\end{array}$ & 0.0422 & 0.0586 & 0.0682 & 0.0753 & 0.0783 & 0.0557 \\
\hline $\begin{array}{c}\mathrm{Cu}+\mathrm{AZ}+ \\
\mathrm{PMMA}\end{array}$ & $\begin{array}{l}1628 \mathrm{~cm}^{-1} \\
\mathrm{C}=\mathrm{N}(\mathrm{Cu})\end{array}$ & 0.0019 & 0.0026 & 0.0020 & -0.0034 & 0.0039 & 0.0019 \\
\hline $\begin{array}{c}\text { Zn+AZ+ } \\
\text { PMMA }\end{array}$ & $\begin{array}{l}1610 \mathrm{~cm}^{-1} \\
\mathrm{C}=\mathrm{N}(\mathrm{Zn})\end{array}$ & 0.0209 & 0.0115 & 0.0202 & 0.0113 & 0.0140 & 0.0167 \\
\hline
\end{tabular}

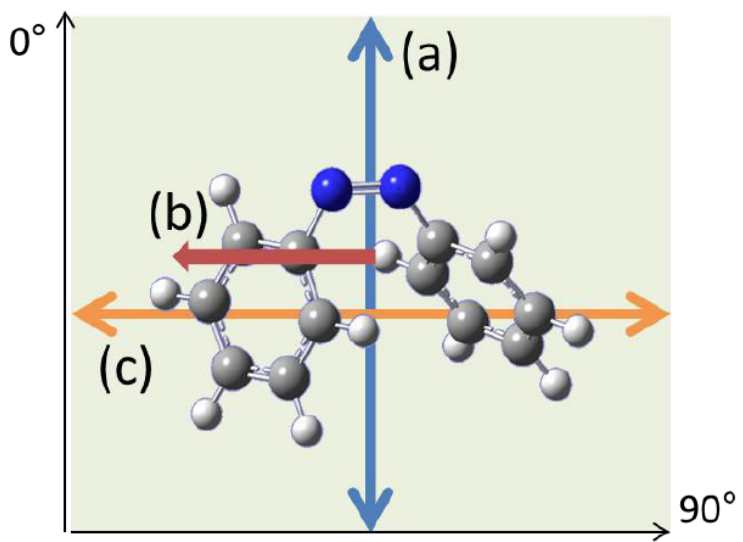

Figure 9: Expected molecular orientation of $\mathbf{A Z}$ on the basis of polarized UV-vis spectra: (a) irradiated polarized light (electric vector), (b) transition dipole moment (AZ), and (c) strong absorption (experimental result).

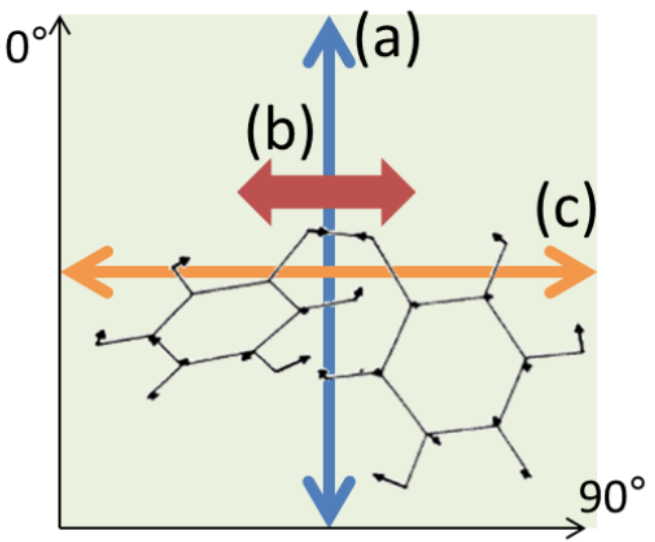

Figure 10: Expected molecular orientation of $\mathbf{A Z}$ from polarized IR spectra: (a) irradiated polarized light (electric vector), (b) $\mathrm{N}=\mathrm{N}$ stretching vibration, and (c) strong absorption (experimental results). 


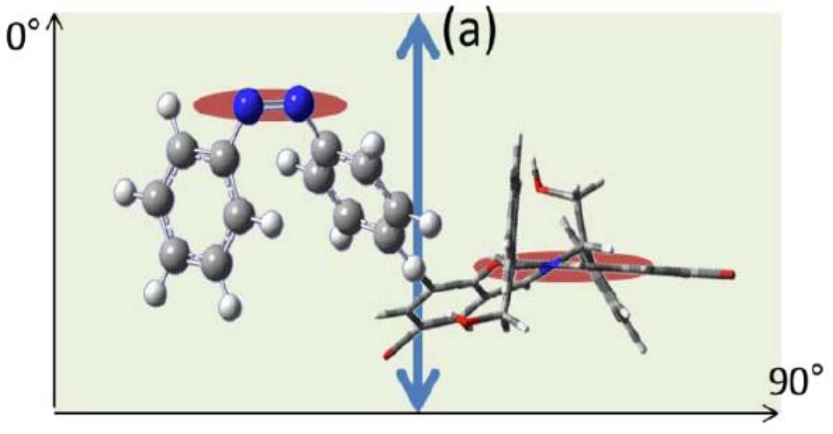

Figure 11: Expected supramolecular orientation of a complex with AZ from polarized IR spectra: (a) irradiated polarized light (electric vector).

\section{Circularly Polarized UV Light-Induced Chiral Supramolecular Arrangement}

We also attempted to induce helical orientation by the irradiation of circularly polarized light onto the hybrid materials. Figure 12 depicts the CD spectra before and after circularly polarized UV light irradiation and their difference spectra. After irradiation for $10 \mathrm{~min}$, new CD peaks appeared at $330 \mathrm{~nm}$. Because complexes do not have peaks in the CD spectra (or UV-vis spectra) in this region [38, 39], this suggests that supramolecular chiral arrangements were induced [66].

\section{CONCLUSION}

We have prepared organic/inorganic hybrid materials $(\mathbf{N i}+\mathbf{A Z}+\mathbf{P M M A}, \mathbf{C u}+\mathbf{A Z}+\mathbf{P M M A}$, and $\mathbf{Z n}+\mathbf{A Z}+\mathbf{P M M A})$ and investigated their light-induced supramolecular orientation using experiments and theoretical calculations. Irradiation of the hybrid materials with linearly polarized light resulted in increased optical anisotropy in each case. Anisotropy of $\mathbf{N i}+\mathbf{A Z}+$ PMMA was increased most markedly. After irradiation with circularly polarized light, new CD peaks emerged, and these were attributed to an induced helical orientation. We could individually observe the molecular orientation of $\mathbf{A Z}$ and complexes by polarized IR measurement. We found a parallel arrangement of $\mathrm{N}=\mathrm{N} \quad(\mathbf{A Z})$ and $\mathrm{C}=\mathrm{N}$ (complexes) bands, which is perpendicular to the electric vector of the irradiated light. This is proof of supramolecular orientation of complexes with transmission from the reorientation of $\mathbf{A Z}$, which is directly rotated by the Weigert effect. The development of other systems for polymer matrices such as proteins [67] for new photofunctional materials is in progress.

\section{SUPPLEMENTARY INFORMATION}

The supplementary information can be downloaded from the journal website along with the article.
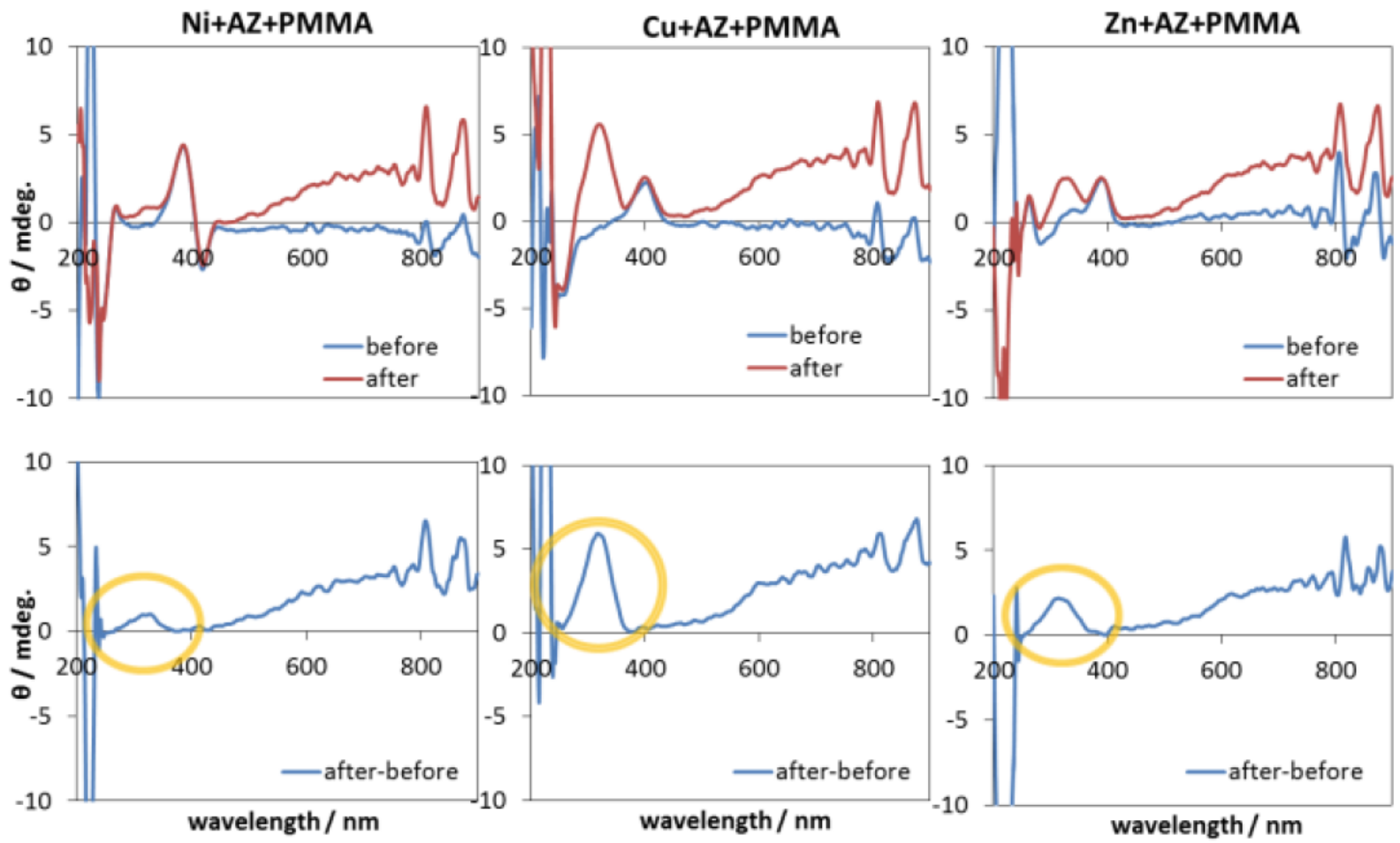

Figure 12: [Above] CD spectra for $\mathbf{N i}+\mathbf{A Z}+\mathbf{P M M A}, \mathbf{C u}+\mathbf{A Z}+\mathbf{P M M A}$, and $\mathbf{Z n}+\mathbf{A Z}+\mathbf{P M M A}$ before and after circularly polarized UV light irradiation. [Below] Difference CD spectra for $\mathbf{N i}+\mathbf{A Z}+\mathbf{P M M A}, \mathbf{C u}+\mathbf{A Z}+\mathbf{P M M A}$, and $\mathbf{Z n}+\mathbf{A Z}+\mathbf{P M M A}$ before and after circularly polarized UV light irradiation. 


\section{REFERENCES}

Cao J, Liu L-H, Fang W-H, Xie Z-Z, Zhang Y. Photo-induced Isomerization of Ethylene-bridged Azobenzene Explored by ab initio Based Non-adiabatic Dynamics Simulation: A Comparative Investigation of the Isomerization in the Gas and Solution Phases. J Chem Phys 2013; 138: 134306. http://dx.doi.org/10.1063/1.4798642

[2] Böckmann M, Doltsinis NL, Marx D. Enhanced photoswitching of bridged azobenzene studied by nonadiabatic ab initio simulation. J Chem Phys 2012; 137: 22A505.

[3] Pederzoli M, Pittner J, Barbatti M, Lischka H. Cis-trans photoisomerization of azobenzene upon excitation to the S1 state: An ab initio molecular dynamics and QM/MM study, in Nanoengineering: Fabrication, Properties, Optics, and Devices IX, Proceedings of SPIE, vol. 8463, Article Number: 846318, Dobisz EA, Eldada LA, Eds., SPIE-INT SOC OPTICAL ENGINEERING, 2012.

[4] Zhou Y-H, Yuan L-Z, Zheng X-H. Ab initio study of the transport properties of a light-driven switching molecule azobenzene substituent. Comp Mater Sci 2012; 61: 145-9. http://dx.doi.org/10.1016/j.commatsci.2012.04.024

[5] Fan Z-Q, Zhang Z-H, Qiu M, Deng X-Q, Tang G-P. Controllable negative differential resistance behavior of an azobenzene molecular device induced by different moleculeelectrode distances. Chin Phys Lett 2012; 29: 077305. http://dx.doi.org/10.1088/0256-307X/29/7/077305

[6] Cusati T, Granucci G, Martínez-Núñez E, Martini F, Persico M, Vázquez S. Semiempirical Hamiltonian for simulation of azobenzene photochemistry. J Phys Chem A 2012; 116: 98110.

http://dx.doi.org/10.1021/jp208574q

[7] Dong Z, Seemann NM, Lu N, Song Y. Effects of high pressure on azobenzene and hydrazobenzene probed by Raman spectroscopy. J Phys Chem B 2011; 115: 14912-18. http://dx.doi.org/10.1021/jp207170w

[8] Pederzoli M, Pittner J, Barbatti M, Lischka H. Non-adiabatic molecular dynamics study of the cis-trans photoisomerization of azobenzene excited to the $S_{1}$ state. $J$ Phys Chem A 2011; 115: 11136-43. http://dx.doi.org/10.1021/jp2013094

[9] Liu L, Yuan S, Fang W-H, Zhang Y. Probing highly efficient photoisomerization of a bridged azobenzene by a combination of CASPT2//CASSCF calculation with semiclassical dynamics simulation. J Phys Chem A 2011; 115: 10027-34.

http://dx.doi.org/10.1021/jp203704x

[10] Wang L, Zou H, Yi C, Xu J, Xu W. On the spectra and isomerization of azobenzene attached non-covalently to an armchair $(8,8)$ single-walled carbon nanotube. Dyes Pigments 2011; 89: 290-6. http://dx.doi.org/10.1016/j.dyepig.2010.04.003

[11] Jacquemin $\mathrm{D}$, Laurent $\mathrm{AD}$, Perpète EA, André J-M. An $a b$ initio simulation of the UV/visible spectra of $\mathrm{N}$ benzylideneaniline dyes. Int J Quantum Chem 2009; 109: 3506-15.

http://dx.doi.org/10.1002/qua.22303

[12] Konôpka M, Turansky R, Doltsinis NL, Marx D, Stich I. Azobenzene-Metal Junction as a Mechanically and OptoMechanically Driven Switch. High Perform Comp Sci Eng 2008 - Trans High Perform Comput Center Stuttgart, HLRS 2008; 2009: 95-108.

[13] Crecca CR, Roitberg AE. Theoretical study of the isomerization mechanism of azobenzene and disubstituted azobenzene derivatives. J Phys Chem A 2006; 110: 8188203.

http://dx.doi.org/10.1021/jp057413c
Fliegl H, Köhn A, Hättig C, Ahlrichs R. Ab Initio Calculation of the Vibrational and Electronic Spectra of trans- and cisAzobenzene. J Am Chem Soc 2003; 125: 9821-7. http://dx.doi.org/10.1021/ja0344330

[15] Ishikawa T, Noro T, Shoda T. Theoretical study on the photoisomerization of azobenzene. J Chem Phys 2001; 115 7503.

http://dx.doi.org/10.1063/1.1406975

[16] Tsuji T, Takashima H, Takeuchi H, Egawa T, Konaka S Molecular structure and torsional potential of transazobenzene: a gas electron diffraction study. J Phys Chem A 2001; 105: 9347-53. http://dx.doi.org/10.1021/jp004418v

[17] Armstrong DR, Clarkson J, Smith WE. Vibrational analysis of trans-azobenzene. J Phys Chem 1995; 99: 17825-31. http://dx.doi.org/10.1021/i100051a005

[18] Morley JO. Theoretical calculations of the structure of a donor-acceptor stilbene, azobenzene and related molecules. J Mol Struct (Theochem) 1995; 340: 45-50. http://dx.doi.org/10.1016/0166-1280(95)04213-P

[19] Akitsu T, Nishijo J. The first detection of photomodulation by both DC and in-phase AC susceptibility for organic/inorganic hybrid materials containing cyano-bridged $\mathrm{Gd}-\mathrm{Cr}$ complex and azobenzene. J Magn Magn Mater 2008; 320: 1586-90. http://dx.doi.org/10.1016/j.jmmm.2008.01.008

[20] Akitsu T, Einaga Y. Syntheses, crystal structures, and electronic properties of a series of copper(II) complexes with 3,5-halogen-substituted Schiff base ligands and their solutions. Polyhedron 2005; 24: 2933-43. http://dx.doi.org/10.1016/i.poly.2005.06.018

[21] Akitsu T, Einaga Y. Synthesis, crystal structures and electronic properties of Schiff base nickel (II) complexes: Towards solvatochromism induced by a photochromic solute. Polyhedron 2005; 24: 1869-77. http://dx.doi.org/10.1016/i.poly.2005.06.019

[22] Akitsu T. Photofunctional supramolecular solution systems of chiral Schiff base nickel(II), copper(II), and zinc(II) complexes and photochromic azobenzenes. Polyhedron 2007; 26: 2527 35.

http://dx.doi.org/10.1016/j.poly.2006.12.031

[23] Akitsu T, Itoh T. Polarized spectroscopy of hybrid materials of chiral Schiff base cobalt(II), nickel(II), copper(II), and zinc(II) complexes and photochromic azobenzenes in PMMA films. Polyhedron 2010; 29: 477-87. http://dx.doi.org/10.1016/j.poly.2009.06.050

[24] Akitsu T, Ishioka C. Manipulation and observation by polarized light: hybrid materials of chiral schiff base $\mathrm{Mn}$ (III) complexes and azobenzene in PMMA. Asian Chem Lett 2010; 14: 37-51.

[25] Akitsu T, Tanaka R. Polarized electronic and IR spectroscopy of hybrid materials of chiral $\mathrm{Cu}(\mathrm{II})$ and $\mathrm{Mn} 12$ complexes and some photochromic compounds in PMMA films. Asian Chem Lett 2010; 14: 235-54.

[26] Aritake T, Takanashi T, Yamazaki A, Akitsu T. Polarized spectroscopy and hybrid materials of chiral Schiff base Ni(II) $\mathrm{Cu}(\mathrm{II}), \mathrm{Zn}(\mathrm{II})$ complexes with included or separated azogroups. Polyhedron 2011; 30: 886-94.

http://dx.doi.org/10.1016/i.poly.2010.12.015

[27] Akitsu T, Miura Y. Polarized electronic spectra of organic/inorganic hybrid materials of chiral Schiff base Ni(II) or $\mathrm{Cu}(\mathrm{II})$ complexes and disperse red 1 or azobenzene in PMMA films. J Chem Chem Eng 2011; 5: 443-50.

[28] Aritake Y, Akitsu T. The role of chiral dopants in organic/inorganic hybrid materials containing chiral Schiff base $\mathrm{Ni}(\mathrm{II}), \mathrm{Cu}(\mathrm{II})$ and $\mathrm{Zn}(\mathrm{II})$ complexes. Polyhedron 2012; 31: 278-84.

http://dx.doi.org/10.1016/i.poly.2011.09.025 
[29] Yamazaki A, Akitsu T. Polarized spectroscopy and polarized UV light-induced molecular orientation of chiral diphenyl Schiff base $\mathrm{Ni}(\mathrm{II})$ and $\mathrm{Cu}(\mathrm{II})$ complexes and azobenzene in a PMMA film. RSC Adv 2012; 2: 2975-80.

http://dx.doi.org/10.1039/c2ra00407k

[30] Aritake Y, Takanashi T, Yamazaki A, Akitsu T. Magnets: Types, Uses and Safety, Nova Science Publishers, Inc. 2012; 85.

[31] Yamazak A, Akitsu T. Magnets: Types, Uses and Safety, Nova Science Publishers, Inc. 2012; 51.

[32] Yamazaki A, Kominato C, Matsuoka S, Watanabe Y, Akitsu T, Integrating Approach to Photofunctional Hybrid Materials for Energy and the Environment, Nova Science Publishers, Inc. 2013; 125

[33] Natansohn A, Rochon P. Photoinduced motions in azocontaining polymers. Chem Rev 2002; 102: 4139-75. http://dx.doi.org/10.1021/cr970155y

[34] Tanaka R, Akitsu T. Polarized electronic and IR spectra of hybrid materials of chiral $\mathrm{Mn}$ (II) complexes and different types of photochromic dyes showing photoisomerization or weigert effect. Curr Phys Chem 2011; 1: 82-9. http://dx.doi.org/10.2174/1877946811101020082

[35] Okamoto Y, Nidaira K, Akitsu T. Environmental dependence of artifact CD peaks of chiral schiff base $3 d-4 f$ complexes in soft mater PMMA matrix. Int J Mol Sci 2011; 12: 6966-79. http://dx.doi.org/10.3390/ijms12106966

[36] Hattori K, Okamoto Y, Kominato C, Akitsu T. PMMA matrix viscosity dependence of $C D$ bands of flexible chiral schiff base $\mathrm{Ni}(\mathrm{II}), \mathrm{Cu}(\mathrm{II})$, and $\mathrm{Zn}(\mathrm{II})$ complexes. Comtemp Eng Sci 2014; 7: 853-9.

[37] Okamoto Y, Nidaira K, Akitsu T. Crystallography: Research, Technology and Applications, Nova Science Publishers, Inc. 2012; 119.

[38] Ito M, Akitsu T. Polarized UV light induced molecular arrangement depending on flexibility of chiral schiff base $\mathrm{Ni}(\mathrm{II}), \mathrm{Cu}(\mathrm{II})$, and $\mathrm{Zn}(\mathrm{II})$ complexes by azobenzene in PMMA matrix. Contemp Eng Sci 2014; 7: 869-77.

[39] Hariu N, Ito M, Akitsu T. Linearly, circularly, or non-polarized light induced supramolecular arrangement of diastereomer schiff base $\mathrm{Ni}$ (II), $\mathrm{Cu}$ (II), and Zn (II) complexes by azobenzene in PMMA matrix. Contemp Eng Sci 2015; 8: 5770.

[40] Gaussian 09, Revision D.01, Frisch MJ, Trucks GW, Schlegel HB, Scuseria GE, Robb MA, Cheeseman JR, Scalmani G, Barone V, Mennucci B, Petersson GA, Nakatsuji $\mathrm{H}$, Caricato M, Li X, Hratchian HP, Izmaylov AF, Bloino J, Zheng G, Sonnenberg JL, Hada M, Ehara M, Toyota K, Fukuda R,. Hasegawa J, Ishida M, Nakajima T, Honda $Y$, Kitao O, Nakai H, Vreven T, Montgomery, Jr. JA, Peralta JE, Ogliaro F, Bearpark M, Heyd JJ, Brothers E, Kudin KN, Staroverov VN, Kobayashi R, Normand J, Raghavachari K, Rendell A, Burant JC, lyengar SS, Tomasi J, Cossi M, Rega $\mathrm{N}$, Millam JM, Klene M, Knox JE, Cross JB, Bakken V, Adamo C, Jaramillo J, Gomperts R, Stratmann RE, Yazyev O, Austin AJ, Cammi R, Pomelli C, Ochterski JW, Martin RL, Morokuma K, Zakrzewski VG, Voth GA, Salvador P, Dannenberg JJ, Dapprich S, Daniels AD, Farkas Ö, Foresman JB, Ortiz JV, Cioslowski J, Fox DJ, Gaussian, Inc., Wallingford CT, 2009.

[41] Palafox MA, Núñez JL, Gil M, Rastogi VK. Perspectives in Engineering Optics, Singh K, Rastogi VK, Eds. Anita Publications, Delhi-Ghaziabad 2002; 356.

[42] Palafox MA. Structure and conformational analysis of the anti-HIV reverse transcriptase inhibitor AZT using MP2 and DFT methods. Differences with the natural nucleoside thymidine. Simulation of the 1st phosphorylation step with ATP. Phys Chem Chem Phys 2014; 16: 24763-83.

[43] Palafox MA, Bhat D, Goyal Y, Ahmad S, Joe IH, Rastogi VK. FT-IR and FT-Raman spectra, MEP and HOMO-LUMO of 2,5-dichlorobenzonitrile: DFT study. Spectrochim Acta A 2015; 136: 464-72.

http://dx.doi.org/10.1016/j.saa.2014.09.058

[44] Molina AT, Palafox MA. Structure and conformational analysis of the anti-HIV AZT 5'-aminocarbonylphosphonate prodrug using DFT methods. Chem Phys 2011; 387: 11-24. http://dx.doi.org/10.1016/j.chemphys.2011.06.022

[45] Palafox MA, Posada-Moreno P, Villarino-Marín AL, MartinezRincon C, Ortuño-Soriano I, Zaragoza-García I. DFT calculation of four new potential agents muscarinic of bispyridinium type: structure, synthesis, biological activity, hydration, and relations with the potents W84 and DUO-3O. J Comp Aided Molec Design 2011; 25: 145-61. http://dx.doi.org/10.1007/s10822-010-9406-9

[46] Palafox MA, Nielsen OF, Lang K, Garg P, Rastogi VK. Geometry and vibrational spectra of 5-substituted uracils. Asian Chem Lett 2004; 8: 81-93.

[47] Palafox MA, Rastogi VK. Quantum chemical predictions of the vibrational spectra of polyatomic molecules. The uracil molecule and two derivatives. Spectrochim Acta A Mol Biomol Spectrosc 2002; 58: 411.

[48] Palafox MA. Recent Res Devel in Phys Chem Transworld Research Network, India 1998; 2: 213.

[49] Palafox MA. Scaling factors for the prediction of vibrational spectra. I. Benzene molecule. Int J Quantum Chem 2000; 77: 661-84.

[50] Palafox MA, Iza N, Gil M. The hydration effect on the uracil frequencies: an experimental and quantum chemical study. $J$ Mol Struct (Theochem) 2002; 585: 69-92. http://dx.doi.org/10.1016/S0166-1280(02)00033-7

[51] Zhao Y, Truhlar DG. Applications and validations of the Minnesota density functionals. Chem Phys Lett 2011; 502: 113 http://dx.doi.org/10.1016/j.cplett.2010.11.060

[52] Carpenter JE, Weinhold F. Analysis of the geometry of the hydroxymethyl radical by the "different hybrids for different spins" natural bond orbital procedure. J Mol Struct (Theochem) 1988; 169: 41-62.

http://dx.doi.org/10.1016/0166-1280(88)80248-3

[53] Reed AE, Curtiss LA, Weinhold F. Intermolecular interactions from a natural bond orbital, donor-acceptor viewpoint. Chem Rev 1988; 88: 899-926.

http://dx.doi.org/10.1021/cr00088a005

[54] Gagliardi L, Orlandi G, Bernardi F, Cembran A, Garavelli M. A theoretical study of the lowest electronic states of azobenzene: the role of torsion coordinate in the cis-trans photoisomerization. Theor Chem Acc 2004; 111: 363-72. http://dx.doi.org/10.1007/s00214-003-0528-1

[55] Tsuji T, Takashima H, Takeuchi H, Egawa T, Konaka S. Molecular structure and torsional potential of transazobenzene. A gas electron diffraction study. J Phys Chem A 2001; 105: 9347-53. http://dx.doi.org/10.1021/jp004418v

[56] Palafox MA, Núñez JL, Gil M. Accurate scaling of the vibrational spectra of aniline and several derivatives. $\mathrm{J}$ Mol Struct (Theochem) 2002; 593: 101-31. http://dx.doi.org/10.1016/S0166-1280(02)00319-6

[57] Meić Z, Baranović G, Smrečki V, Novak P, Keresztury G, Holly S. Vibrational coupling in trans-azobenzene and its isotopomers. J Mol Struct 1997; 408-409: 399-403.

[58] Stepanić V, Baranović G, Smrečki V. Structure and vibrational spectra of conjugated Acids of trans- and cisazobenzene. J Mol Struct 2001; 569: 89-109. http://dx.doi.org/10.1016/S0022-2860(00)00967-4

[59] Kellerer B, Hacker $\mathrm{H}$, Brandmüller J. On the structure of azobenzene and tolane in solution: Raman spectra of azobenzene, azobenzene-c/ю, p,p '-azobenzene-^, azobenzene- $15 \mathrm{~N}=15 \mathrm{~N}$ and tolane. Ind J Pure Appl Phys 1971; 9: 903-9. 
[60] Gruger A, Le Calvé N, Dizabo P, Fillaux J. J Chim Phys 1972; 69: 291.

[61] Varsanyi G, Assignments for vibrational Spectra of Seven hundred benzene derivatives, Vol 1, (Adam Hilger, London) $1974 ; 280$.

[62] Agarwal P, Bee S, Gupta A, et al. Quantum chemical study on influence of intermolecular hydrogen bonding on the geometry, the atomic charges and the vibrational dynamics of 2,6-dichlorobenzonitrile. Spectrochim Acta A 2014; 121: 464-82.

http://dx.doi.org/10.1016/..saa.2013.10.104

[63] Shishkin OV, Pelmenschikov A, Hovorun DM, Leszczynski J. Theoretical analysis of low-lying vibrational modes of free canonical 2-deoxyribonucleosides. Chem Phys 2000; 260: 317-25.

http://dx.doi.org/10.1016/S0301-0104(00)00251-2

[64] Hovorun DM, Mishchuk TR, Yurenko YP. Biopolymer Cell 2002; 18: 219.

[65] Martel P, Hennion B, Durand D, Calmettes P. Low-frequency vibrations of a nucleoside analog. J Biomol Struct Dyn 1994; 12: 401-11.

http://dx.doi.org/10.1080/07391102.1994.10508748

[66] unaga N, Furuya S, Ito M, Kominato C, Akitsu T Computational Chemistry: Theory, Methods and Applications, Nova Science Publishers, Inc. 2014; 85.

[67] Kominato C, Akitsu T. Lett Appl Nano BioSci 2015; 2: 264.

Received on 01-09-2015

Accepted on 11-11-2015

Published on 26-02-2016

DOI: http://dx.doi.org/10.6000/1929-5030.2016.05.01.3

(C) 2016 Ito et al.; Licensee Lifescience Global.

This is an open access article licensed under the terms of the Creative Commons Attribution Non-Commercial License (http://creativecommons.org/licenses/by-nc/3.0/) which permits unrestricted, non-commercial use, distribution and reproduction in any medium, provided the work is properly cited. 